\title{
The Role of Multiplier Bounds in Fuzzy Data Envelopment Analysis
}

\author{
Adel Hatami-Marbini \\ Department of Strategic Management and Marketing \\ Leicester Business School \\ De Montfort University \\ Hugh Aston building, The Gateway, Leicester LE1 9BH, UK \\ E-mail: adel.hatamimarbini@dmu.ac.uk \\ Per J. Agrell ${ }^{1 *}$ \\ Louvain School of Management \\ Center of Operations Research and Econometrics (CORE) \\ Université catholique de Louvain \\ 34 voie du roman pays, L1.03.01 B-1348 Louvain-la-Neuve, Belgium \\ Tel.+32.10 474305; Fax.+32.10474324 \\ E-mail: per.agrell@uclouvain.be \\ Hirofumi Fukuyama \\ Faculty of Commerce \\ Fukuoka University \\ 8-19-1 Nanakuma, Jonan-Ku, Fukuoka City, Fukuoka 814-0180, Japan \\ Email: fukuyama@fukuoka-u.ac.jp \\ Kobra Gholami \\ Department of Science, Bushehr Branch \\ Islamic Azad University, Bushehr, Iran \\ E-mail: k.gholami@srbiau.ac.ir \\ Pegah Khoshnevis \\ Department of Strategy, Innovation and Entrepreneurship (SIE) \\ Faculty of Economics and Business \\ KU Leuven University \\ Warmoesberg 26, 1000, Brussels, Belgium \\ E-mail:pegah.hajimirzakhoshnevis@ kuleuven.be
}

${ }^{1}$ Corresponding author 


\title{
The role of multiplier bounds in fuzzy data envelopment analysis
}

\begin{abstract}
The non-Archimedean epsilon $\varepsilon$ is commonly considered as a lower bound for the dual input weights and output weights in multiplier data envelopment analysis (DEA) models. The amount of $\varepsilon$ can be effectively used to differentiate between strongly and weakly efficient decision making units (DMUs). The problem of weak dominance particularly occurs in Fuzzy Data Envelopment Analysis where the reference set is fully or partially defined in terms of fuzzy numbers. In this paper, we propose a new four-step fuzzy DEA method to re-shape weakly efficient frontiers along with revisiting the efficiency score of DMUs in terms of perturbing the weakly efficient frontier. This approach eliminates the non-zero slacks in fuzzy DEA while keeping the strongly efficient frontiers unaltered. In comparing our proposed algorithm to an existing method in the recent literature we show three important flaws in their approach that our method addresses. Finally, we present a numerical example in banking with a combination of crisp and fuzzy data to illustrate the efficacy and advantages of the proposed approach.
\end{abstract}

Keywords: Data envelopment analysis; Epsilon; Fuzzy data; Weak frontier.

JEL Classification C61 D20 D80

\section{Introduction}

Data envelopment analysis (DEA) introduced by Charnes et al. (1978) is a common nonparametric tool that evaluates the relative efficiency measurement of a group of production processes, frequently referred to as decision making units (DMUs). The seminal radial CCR model is referred to as the input-oriented (output-oriented) model in which inputs (outputs) are proportionally reduced (expanded) while outputs (inputs) remain unchanged.

The flexibility of the DEA models implies that the weights (multipliers) change across the frontier for a non-degenerate data set, making each DMU appear in its most favorable light. Hence, the multiplier DEA models often generate a large number of zero valued weights. Charnes et al. (1979) and Charnes and Cooper (1984) defined strictly positive weights by considering a non-Archimedean infinitesimal $\varepsilon$ as a lower bound for dual weights.

Ali and Seiford (1993) proposed a method for determining an upper bound of $\varepsilon$ such that the feasibility of the multiplier model and boundedness of the envelopment model are preserved. However, Mehrabian et al. (2000) highlighted that the upper bound for $\varepsilon$ in the CCR and BCC 
models defined by Ali and Seiford (1993) cannot guarantee feasibility of the multiplier model nor boundedness of the envelopment model. Mehrabian et al. (2000) then proposed a procedure to identify an assurance interval for $\varepsilon$. Amin and Toloo (2004) proposed an polynomial-time algorithm for computing $\varepsilon$ where this algorithm is polynomial-time with respect to the number of DMUs. Alirezaee (2005) extended Mehrabian et al. (2000)'s method for specifying an overall assurance interval of $\varepsilon$ that was more computationally efficient. Jahanshahloo and Khodabakhshi (2004) introduced a procedure to calculate an assurance bound of $\varepsilon$ such that the envelopment model is bounded and the dual model is feasible. Alirezaee and Khalili (2006) used a counterexample to demonstrate that the overall assurance interval of $\varepsilon$ proposed by Mehrabian et al. (2000) may lead to incorrect detection of the efficient and inefficient DMUs. To deal with the problem, they proposed an $\varepsilon$ independent model that was capable of classifiying strongly efficient, weakly efficient and inefficient DMUs.

The frontier of the production possibility set (PPS) used for evaluation of DMU in DEA may not be Pareto-efficient. This problem stems from zero-valued dual weights (multipliers) (or equivalently strictly positive values for the optimal slacks) for certain weakly efficient DMUs. Bessent et al. (1988) used the extrapolated efficient facets to deal with the non-zero slacks. However, the constrained facet analysis proposed by Bessent et al. (1988) cannot be applied when extreme efficient DMUs span a non full-dimensional efficient facet $\left(\mathrm{FDEF}^{2}\right)$. In the presence of at least m+s-1 CCR extreme efficient DMUs, Green et al. (1996) proposed a mixedbinary linear problem to deal with the non-zero slacks. Chen et al. (2003) calculated the lower bounds using the strong complementary slackness condition (SCSC) for extreme efficient DMUs so as to treat non-zero slack values in DEA.

In general, management information systems and decision support systems are designed to provide managerial information about past and current process resources and outcomes. However, information that may comprise uncertainty ${ }^{3}$, incompleteness, or fuzziness ${ }^{4}$ cannot be handled by these systems, although this type of information may be vital for undertaking

\footnotetext{
${ }^{2}$ A FDEF refers to a facet on which $\mathrm{m}+\mathrm{s}-1$ linearly independent efficient DMUs lie under CCR model where $\mathrm{m}$ and $\mathrm{s}$ are the numbers of inputs and outputs, respectively.

${ }^{3}$ The notion of "uncertainty" has a general meaning, depending on context and discipline. It can be considered as an umbrella term that covers several semi-related concepts connected with "lack of certainty" in reasoning, thereby, uncertainty involve vagueness, imprecision, ambiguity, indeterminacy, missing information, error and so on (Bammer and Smithson, 2008).

${ }^{4}$ Fuzziness is the cause of not only vague relationships (i.e., non-bivalence), but also a plentiful amount of information in which these types of fuzziness have been called "intrinsic fuzziness" and "informational fuzziness", respectively (Zimmermann,1987).
} 
managerial action. Moreover, separate and incompatible information systems gathering production data from distinct stages of a production process may lead to "noise" or measurement errors. In this respect, conventional DEA models also detract attention from uncertainty such as linguistic, interval, ordinal, and ratio interval data. This problem has been dealt with in the DEA literature in different ways. The exclusion of units with uncertain data from the analysis is the simplest method, although the use of such outlier detection and removal may substantially change the level and shape of the non-parametric frontier (Simar and Wilson, 2000, Agrell and Niknazar, 2014).

To deal with uncertainty in DEA, the particular focus of the researchers is on two approaches; stochastic DEA first proposed by Land et al. (1993) and fuzzy DEA first proposed by Sengupta (1992).

Stochastic DEA, also called Chance-constrained DEA, can be used in the case of stochastic data in production relationships (e.g., unpredictable weather in agriculture) (Land et al., 1993; Olesen and Petersen, 1995). When the production plans are fuzzy, the fuzzy DEA approach brings the performance evaluation into action to conquer "vagueness" 5 . This stems from the fuzzy set theory and fuzzy mathematical programming initiated by Zadeh (1965) and further extended by Zimmermann (1996).

The relative merits and complementarity of fuzzy and stochastic programming models have been widely discussed. The fuzzy modelling approach enjoys an undisputable success in computer science, mathematical and engineering applications. However, we face situations in which classical probability cannot be computationally efficient as specified by Kolmogorov's axioms.

Stochastic DEA requires either a priori predictable regularity or a posteriori outcome data, which may not be easy or possible to build for settings where the event is unique or deterministic. On the other hand the fuzzy DEA approach draws on vague values represented by membership functions of the fuzzy sets theory (Triantis and Girod 1998; Hatami-Marbini et al. 2013). It is necessary to point out that the preciseness requires more data, normally more costly to obtain for organizations. Triantis (2011) states that "data necessary for the fuzzy approach, stochastic

\footnotetext{
${ }^{5}$ Two main categories of uncertainty are linked with the terms "vagueness" and "ambiguity", in which vagueness is connected with the hurdle of making precise distinctions while ambiguity is connected with one-to-many relations, i.e., situations with two or more alternatives that remain unspecified. While the concept of a fuzzy set represents a basic mathematical framework for dealing with vagueness, the concept of a fuzzy measure is a general framework for dealing with ambiguity (Klir, 1987).
} 
approach, and the crisp DEA approach could be obtained at a cost ranging in the hundreds, tens of thousands, and millions of dollars, respectively". For these reasons, fuzzy set theory has gradually been applied into DEA models so as to provide an alternative modeling avenue under uncertainty. Hatami-Marbini et al. (2011) and Emrouznejad et al. (2014) are examples of recent surveys of fuzzy DEA methods, distinguishing six categories in the literature viz. (1) the tolerance approach (e.g. Sengupta 1992), (2) the $\alpha$-level based approach (e.g. Kao and Liu, 2000; Hatami-Marbini and Saati, 2009; Ignatius et al. 2016), (3) the fuzzy ranking approach (e.g., Guo and Tanaka, 2001), (4) the possibility approach (Lertworasirikul et al., 2003) (5) the fuzzy arithmetic (e.g., Wang et al. 2009), and (6) the fuzzy random/type-2 (e.g., Qin et al. 2009). Besides these main categories, we may add the fuzzy clustering and dominance methods (e.g., Triantis and Eeckaut, 2000; Triantis et al., 2003; Seaver et al. 2004) that have received significantly less attention in the literature. As concluded in Hatami-Marbini et al. (2011), the fuzzy DEA literature primarily focuses on theoretical perspectives while its practical (societal) utility still remains unclear and requires much further investigation.

The main idea of the $\alpha$-level based approach as the most widespread fuzzy DEA method is to convert the fuzzy DEA model into a pair of parametric models for calculating the lower and upper bounds of the efficiency at a given $\alpha$. As a consequence, the imprecise DEA model involving interval data can be a special case of the $\alpha$-level based approach of fuzzy DEA model for a specified $\alpha$. The current literature on different DEA models for interval data is rich (cf. e.g., Despotis and Smirlis 2002; Shokouhi et al. 2010, 2014; Emrouznejad et al. 2011, 2012). Despotis and Smirlis (2002) proposed a pair of models to calculate the lower and upper bounds of the efficiency where data are characterized by interval quantities. To evaluate a given DMU they used two different technologies for the pessimistic and optimistic viewpoints. Wang et al. (2005) modified Despotis and Smirlis (2002)'s method by using a fixed technology in evaluating the interval efficiency of a DMU.

In the fuzzy DEA literature, Khoshfetrat and Daneshvar (2011) introduced a framework to identify the weakly efficient DMUs for the case of fuzzy inputs and outputs. Their approach determines a lower bound for each input weight, $\varepsilon_{i}$, and output weight, $\varepsilon_{r}$, respectively. Prior to calculating the radial efficiency projections, the fuzzy data is transformed to interval data using the $\alpha$-level approach and Despotis and Smirlis (2002)'s method is then applied for all $\alpha$-levels.

The contribution of this paper is a new four-step imprecise DEA method for characterizing 
weakly efficient frontiers by defining an $\varepsilon$ associated with inputs and outputs while guaranteeing a feasible solution. The method draws on the classification into four classes of strictness of efficiency, as in Charnes et al. (1991), based on their efficiency scores and optimal slacks. We compare our results with those obtained by the method in Khoshfetrat and Daneshvar (2011), proving three important flaws in their solution to the problem.

The rest of this paper is organized as follows: Section 2 reviews the conventional DEA models and discuss multiplier bounds in DEA followed by overviewing imprecise DEA formulations. In Section 3, we present a four-step fuzzy DEA method for re-shaping weakly efficient frontiers along with modifying the efficiency score of DMUs in terms of perturbing the weakly efficient frontier. We demonstrate the shortcomings of the Khoshfetrat and Daneshvar (2011) method in Section 4. In Section 5, we present a numerical example to illustrate the proposed method in this study. Finally, we provide some concluding remarks in Section 6.

\section{Performance evaluation}

In this section, we present some basic DEA formulations, weight bounds in DEA and imprecise DEA models used throughout the paper.

\subsection{Conventional DEA models}

Data envelopment analysis (DEA) as a nonparametric technique has been frequently applied to measure the relative efficiency of a set of Decision-Making units (DMUs).

Assume that there are $n$ DMUs in a reference set of observations where the $j$ th $(j=1, \ldots, n)$ observation is characterized by an input vector $x_{j} \in \mathbb{R}^{1 \times m}$ and an output vector $y_{j} \in \mathbb{R}^{1 \times s}$. Specifically, $\mathrm{DMU}_{\mathrm{o}}$ consumes an amount $x_{i o}>0$ of input $i$ to produce an amount $y_{r o}>0$ of output $r$. The $s \times n$ output matrix is denoted by $Y$, and the $m \times n$ input matrix is denoted by $X$. The corresponding linear programming problem for the radial (input-oriented) $\mathrm{CCR}^{6}$ model (socalled multiplier CCR or dual problem) and its primal formulation, (which is called envelopment $\mathrm{CCR})$, are presented to evaluate $\mathrm{DMU}_{\mathrm{o}}$ consisting of $\left(x_{o}, y_{o}\right)$ as follows (Charnes et al. 1978):

\footnotetext{
${ }^{6} \mathrm{CCR}$ is also known as CRS (Constant-Returns-to-Scale) model.
} 


\section{(1-1) Multiplier CCR model}

$\max u y_{o}$

s.t. $\quad v x_{o}=1$,

$u Y-v X \leq 0$,

$u, v \geq 0$.

\section{(1-2) Envelopment CCR model}

$\min \theta_{o}$

s.t. $\quad \lambda X-\theta_{o} x_{o} \leq 0$,

$\lambda Y-y_{o} \geq 0$,

$\lambda \geq 0$.

where $u$ and $v$ are the non-negative weights vectors associated with output and input, respectively. Charnes et al. (1985) introduced the additive model combining both orientations as follows:

(2-1) Dual additive model

$\max u y_{o}-v x_{o}$

s.t. $\quad u Y-v X \leq 0$,

$u, v \geq 1$.
(2-2) Primal additive model

$$
\begin{array}{ll}
\min & -\left(s^{+}+s^{-}\right) \\
\text {s.t. } & \lambda X-x_{o}+s^{+}=0, \\
& \lambda Y-y_{o}-s^{-}=0, \\
& \lambda, s^{+}, s^{-} \geq 0 .
\end{array}
$$

The direct slacks in the additive model, the input excesses $s^{+}$and output shortfalls $s^{-}$can be used to identify the efficiency. $\mathrm{DMU}_{\mathrm{o}}$ is called efficient if and only if $s^{-*}=0$ and $s^{+^{*}}=0$ in model (2-2); otherwise, $\mathrm{DMU}_{\mathrm{o}}$ is called inefficient. The determination of such a framework enables a better interpretation of the definitions of "Pareto-Koopmans" or "strong" efficiency discussed in the next section.

\subsection{Multiplier bounds}

The multiplier model (1-1) often results in a large number of zero-valued weights. Cooper et al. (2002) state that some DMUs may not be (strongly) efficient even if they are presented as (radially) efficient DMUs in conventional codes and software. This dilemma frequently occurs for DMUs that have strong skewness towards one input or output. Charnes et al. (1979) and Charnes and Cooper (1984) modified the multiplier DEA model by prescribing strictly positive weights. As a result, a non-Archimedean infinitesimal $\varepsilon$ was introduced as a lower bound for weights in model (1-1) to detect non-proportional inefficiencies (slacks). The resulting models are stated as follows: 


\section{(3-1) Multiplier CCR model}

$\max \theta_{o}=u y_{o}$

s.t. $\quad v x_{o}=1$,

$u Y-v X \leq 0$,

$u, v \geq \varepsilon$.

\section{(3-2) Envelopment CCR model}

$$
\begin{array}{ll}
\min & w_{o}-\varepsilon\left(s^{+}+s^{-}\right) \\
\text {s.t. } & \lambda X-w_{o} x_{o}+s^{+}=0, \\
& \lambda Y-y_{o}-s^{-}=0, \\
& \lambda, s^{+}, s^{-} \geq 0 .
\end{array}
$$

where $s^{+}$and $s^{-}$are the slack variables used to transform the inequalities in (1-2) to equivalent equations. The efficient DMUs can be divided into two distinct groups: strongly efficient and weakly efficient. In model (3-2), DMU $\mathrm{D}_{\mathrm{o}}$ is strongly efficient iff both (i) $w_{o}^{*}=1$ and (ii) all slacks $s^{+^{*}}=s^{-^{*}}=0$ while $\mathrm{DMU}_{\mathrm{o}}$ is weakly efficient iff both (i) $w_{o}^{*}=1$ and (ii) $s^{+^{*}} \neq 0$ and/or slacks $s^{-*} \neq 0$ for at least one $i$ and $r$.

Note that in solving model (3-2) involving the non-Archimedean infinitesimal $\varepsilon$, simply choosing an arbitrary value for $\varepsilon$ may lead to erroneous results since theoretically it is impossible to represent an infinitesimal quantum within a finite tolerance numerical representation. Indeed, models (3-1) and (3-2) may be infeasible and unbounded, respectively, if the $\varepsilon$ is wrongly defined. The determination of an appropriate value or interval for the non-Archimedean $\varepsilon$ is a challenging and open issue.

Theoretically, the CCR envelopment surface is composed of given facets resulting from the intersection of the half-spaces of supporting hyperplanes that passes through the efficient DMUs and origin. The optimal solutions of model (3-1) yield normal vectors of supporting hyperplanes. If $\left(u^{*}, v^{*}\right)$ are the optimal solutions of model (3-1), a $\mathrm{DMU}_{\mathrm{o}}$ is efficient if it lies on a facetdefining hyperplanes of the envelopment surface; specifically, a hyperplane of the form

$$
u^{*} y_{o}=1=v^{*} x_{o} \rightarrow u^{*} y_{o}-v^{*} x_{o}=0
$$

Thus, $\left(u^{*},-v^{*}\right)$ is the normal vector of supporting hyperplane in conjunction with $\mathrm{DMU}_{\mathrm{o}}$. If all components of vector $\left(u^{*}, v^{*}\right)$ take positive values and $\theta^{*}=1$, then the complementary slackness condition implies that all components of vector $\left(s^{-^{*}}, s^{+^{*}}\right)$ are zero and that $w_{o}^{*}=1$ in the optimal solutions of model (3-2). In this situation the strongly efficient $\mathrm{DMU}_{\mathrm{o}}$ is lying on the technically efficient frontier. On the other hand, if there exists at least one component of vector $\left(u^{*}, v^{*}\right)$ with 
zero value and $\theta_{o}{ }^{*}=1$, then, according to the complementary slackness condition, there exists at least one non-zero component in vector $\left(s^{-^{*}}, s^{+^{*}}\right)$ and $w_{o}^{*}=1$ in the optimal solutions of model (3-2). In this case, $\mathrm{DMU}_{\mathrm{o}}$ is positioned on the weakly efficient frontier. As a result, the normal vector $\left(u^{*},-v^{*}\right)$ of the hyperplane passing through a weakly efficient DMU has at least one zero component causing the hyperplanes associated with the weak frontier to be parallel to at least one axis of inputs or outputs. On a separate interpretation, it is necessary to underline out that the weak efficiency contradicts with the efficiency defined as a non-dominated DMU. To deal with this problem, numerous studies have been implemented to determine the weak efficient DMUs by perturbing the weak efficient frontiers (see e.g., Thanassoulis and Allen, 1998; Allen and Thanassoulis 2004).

\subsection{DEA models for imprecise data}

This paper aims to use the LR-type of fuzzy sets consisting of a wide range of type of fuzzy numbers such as triangular and trapezoidal fuzzy numbers since the computational efficiency is important for implementations (see Zimmermann, 1996). We assume access to $n$ production plans $(j=1, \ldots, n)$ where each production plan consume $m$ fuzzy inputs of the LR-type, denoted by $\tilde{x}_{i j}=\left(x_{i j}^{l}, x_{i j}^{m 1}, x_{i j}^{m 2}, x_{i j}^{u}\right)$ to produce $s$ fuzzy outputs of the LR-type, denoted by $\tilde{y}_{r j}=$ $\left(y_{r j}^{l}, y_{r j}^{m 1}, y_{r j}^{m 2}, y_{r j}^{u}\right)$. The membership function of inputs and outputs for the $j^{\text {th }}$ production plan can defined as follows:

$\mu_{\tilde{x}_{i j}}=\left\{\begin{array}{cl}f^{L}(x), & x_{i j}^{l} \leq x \leq x_{i j}^{m 1} \\ w, & x_{i j}^{m 1} \leq x \leq x_{i j}^{m 2} \\ f^{R}(x), & x_{i j}^{m 2} \leq x \leq x_{i j}^{u} \\ 0, & \text { otherwise }\end{array} \quad \mu_{\tilde{y}_{r j}} \quad=\left\{\begin{array}{cl}f^{L}(x), & y_{r j}^{l} \leq x \leq y_{r j}^{m 1} \\ w, & y_{r j}^{m 1} \leq x \leq y_{r j}^{m 2} \\ f^{R}(x), & y_{r j}^{m 2} \leq x \leq y_{r j}^{u} \\ 0, & \text { otherwise }\end{array}\right.\right.$

If $w=1$, the fuzzy input/output data is called a normal fuzzy number, and if $0<w<1$, it is called a non-normal fuzzy number.

In some situations, these fuzziness definitions can be used to precisely reflect human reasoning such as "poor" ("good") customer service, as well as the measurement of variability during the production process. In other words, the precise production plans can be relaxed by means of weaker assumption of fuzzy production plans. To assure feasibility of the relaxation, the distributions for the fuzzy inputs and outputs should be expressively verified with the experts or decision-makers that have produced them. The fuzzy number can be projected to a closed interval 
of real numbers using $\alpha$-level method to interactively find the most and least plausible bounds for inputs and outputs, denoted by $\left[\left(x_{i j}\right)_{\alpha}^{L},\left(x_{i j}\right)_{\alpha}^{U}\right]$ and $\left[\left(y_{r j}\right)_{\alpha}^{L},\left(y_{r j}\right)_{\alpha}^{U}\right]$ as the $\alpha$-level of $\tilde{x}_{i j}$ and $\tilde{y}_{r j}$, respectively, i.e., $\left[\tilde{x}_{i j}\right]^{\alpha}=\left[\alpha x_{i j}^{m 1}+(1-\alpha) x_{i j}^{l}, \alpha x_{i j}^{m 2}+(1-\alpha) x_{i j}^{u}\right]$ and $\left[\tilde{y}_{r j}\right]^{\alpha}=\left[\alpha y_{r j}^{m 1}+\right.$ $\left.(1-\alpha) y_{r j}^{l}, \alpha y_{r j}^{m 2}+(1-\alpha) y_{r j}^{u}\right]^{7}$

Despotis and Smirlis (2002) used the interval input-output data (i.e., $\alpha=0$ ) to present two multiplier CCR models to determine the lower and upper bounds of the efficiency of $\mathrm{DMU}_{\mathrm{o}}$, denoted by $\left[\left(\theta_{o}^{L}\right)_{\alpha},\left(\theta_{o}^{U}\right)_{\alpha}\right]$, as follows:

\section{(4-1) Lower efficiency}

$$
\begin{aligned}
\max & \left(\theta_{o}^{L}\right)_{\alpha}=\sum_{r=1}^{s} u_{r}\left(y_{r o}\right)_{\alpha}^{L} \\
\text { s.t. } & \sum_{i=1}^{m} v_{i}\left(x_{i o}\right)_{\alpha}^{U}=1, \\
& \sum_{r=1}^{s} u_{r}\left(y_{r o}\right)_{\alpha}^{L}-\sum_{i=1}^{m} v_{i}\left(x_{i o}\right)_{\alpha}^{U} \leq 0, \\
& \sum_{r=1}^{s} u_{r}\left(y_{r j}\right)_{\alpha}^{U}-\sum_{i=1}^{m} v_{i}\left(x_{i j}\right)_{\alpha}^{L} \leq 0, j=1, \ldots, n, j \neq o, \\
& v_{i} \geq 0, u_{r} \geq 0 . \quad i=1, \ldots, m ; r=1, \ldots, s .
\end{aligned}
$$

\section{(4-2) Upper efficiency}

$$
\begin{aligned}
\max & \left(\theta_{o}^{U}\right)_{\alpha}=\sum_{r=1}^{s} u_{r}\left(y_{r o}\right)_{\alpha}^{U} \\
\text { s.t. } & \sum_{i=1}^{m} v_{i}\left(x_{i o}\right)_{\alpha}^{L}=1, \\
& \sum_{r=1}^{s} u_{r}\left(y_{r o}\right)_{\alpha}^{U}-\sum_{i=1}^{m} v_{i}\left(x_{i o}\right)_{\alpha}^{L} \leq 0, \\
& \sum_{r=1}^{s} u_{r}\left(y_{r j}\right)_{\alpha}^{L}-\sum_{i=1}^{m} v_{i}\left(x_{i j}\right)_{\alpha}^{U} \leq 0, j=1, \ldots, n, j \neq o,
\end{aligned}
$$$$
v_{i} \geq 0, u_{r} \geq 0 . \quad i=1, \ldots, m ; r=1, \ldots, s .
$$

where $\left(\theta_{o}^{U}\right)_{\alpha}$ represents the upper bound of best possible relative efficiency for $\mathrm{DMU}_{\mathrm{o}}$ when the production frontier constraints the best situation for $\mathrm{DMU}_{\mathrm{o}}$ (i.e., $\sum_{r=1}^{s} u_{r}\left(y_{r o}\right)_{\alpha}^{U}-\sum_{i=1}^{m} v_{i}\left(x_{i o}\right)_{\alpha}^{L} \leq 0$ ) and the worst situation for the remaining DMUs (i.e., $\left.\sum_{r=1}^{s} u_{r}\left(y_{r j}\right)_{\alpha}^{L}-\sum_{i=1}^{m} v_{i}\left(x_{i j}\right)_{\alpha}^{U} \leq 0, j=1, \ldots, n, j \neq o\right)$, while $\left(\theta_{o}^{L}\right)_{\alpha}$ represents the lower bound of best possible relative efficiency of $\mathrm{DMU}_{\mathrm{o}}$ when the production frontier includes the worst situation for

\footnotetext{
${ }^{7}$ The $\alpha$-cut as a certain type of inference draws conclusions in the presence of uncertainty. Inference in the framework of possibility theory as explained by Zadeh (1979) embraces a four-step procedure that can be respectively designated i) representation, ii) combination, iii) projection, and iv) interpretation. In addition, readers can find attempts and many studies in the field of descriptive statistics with fuzzy data, fuzzy random variables and statistical inference for fuzzy data in Kruse and Meyer (1987) and Viertl (1996).
} 
$\mathrm{DMU}_{\mathrm{o}}$ (i.e., $\left.\sum_{r=1}^{s} u_{r}\left(y_{r o}\right)_{\alpha}^{L}-\sum_{i=1}^{m} v_{i}\left(x_{i o}\right)_{\alpha}^{U} \leq 0\right)$ and the best situation for the remaining DMUs (i.e., $\left.\sum_{r=1}^{s} u_{r}\left(y_{r j}\right)_{\alpha}^{U}-\sum_{i=1}^{m} v_{i}\left(x_{i j}\right)_{\alpha}^{L} \leq 0, j=1, \ldots, n, j \neq o\right)$. When constructing the production frontier the constraint associated with $\mathrm{DMU}_{\mathrm{o}}$ is separate from the $(n-1)$ constraints associated with the rest of the DMUs. Note that $1 \geq\left(\theta_{o}^{U}\right)_{\alpha} \geq\left(\theta_{o}^{L}\right)_{\alpha} \geq 0$ where each observation lies within bounded interval for each $\alpha$-level. The DMUs are classified into three distinct groups $\left\{E^{++}, E^{+}, E^{-}\right\}$by means of the bounds of efficiency score as:

- Group 1: A DMU is classified as $E^{++}$group, so-called "fully efficient", if its optimal lower bound efficiency obtained from (4-1) is the unity, i.e., $E^{++}=\left\{D M U_{j}:\left(\theta_{j}^{L^{*}}\right)_{\alpha}=1\right\}$,

- Group 2: A DMU is classified as $E^{+}$group, so-called "efficient", if its optimal upper bound efficiency obtained from (4-2) is the unity, i.e., $E^{+}=\left\{D M U_{j}:\left(\theta_{j}^{U^{*}}\right)_{\alpha}=1\right\}$,

- Group 3: A DMU is classified as $E^{-}$group, so-called "inefficient", if its optimal upper bound efficiency obtained from (4-2) is less than one, i.e., $E^{-}=\left\{D M U_{j}:\left(\theta_{j}^{U^{*}}\right)_{\alpha}<1\right\}$.

Wang et al. (2005) schematically showed that Despotis and Smirlis (2002)'s method has a shortcoming in using different technologies for measuring the interval efficiency of a DMU. In order to address this problem, Wang et al. (2005) developed the following pair of interval DEA models with the same technology or constraint set that forms a fixed and unified production frontier:

(5-1) Lower efficiency

$\max \left(\theta_{o}^{L}\right)_{\alpha}=\sum_{r=1}^{s} u_{r}\left(y_{r o}\right)_{\alpha}^{L}$

s.t. $\sum_{i=1}^{m} v_{i}\left(x_{i o}\right)_{\alpha}^{U}=1$

$\sum_{r=1}^{s} u_{r}\left(y_{r j}\right)_{\alpha}^{U}-\sum_{i=1}^{m} v_{i}\left(x_{i j}\right)_{\alpha}^{L} \leq 0, j=1, \ldots, n$,

$v_{i} \geq 0, u_{r} \geq 0 . \quad i=1, \ldots, m ; r=1, \ldots, s$.

\section{(5-2) Upper efficiency}

$$
\begin{aligned}
\max & \left(\theta_{o}^{U}\right)_{\alpha}=\sum_{r=1}^{s} u_{r}\left(y_{r o}\right)_{\alpha}^{U} \\
\text { s.t. } & \sum_{i=1}^{m} v_{i}\left(x_{i o}\right)_{\alpha}^{L}=1, \\
& \sum_{r=1}^{s} u_{r}\left(y_{r j}\right)_{\alpha}^{U}-\sum_{i=1}^{m} v_{i}\left(x_{i j}\right)_{\alpha}^{L} \leq 0, j=1, \ldots, n, \\
& v_{i} \geq 0, u_{r} \geq 0 . \quad i=1, \ldots, m ; r=1, \ldots, s .
\end{aligned}
$$


To avoid infeasibility in the above models, the resulting reference set takes into account the optimistic point of view that is the best situation for outputs and the worst situation for inputs (i.e., the most bound of outputs $\left(y_{r j}\right)_{\alpha}^{U}$ and the least bound of inputs $\left(x_{i j}\right)_{\alpha}^{L}$ ). In the Wang et al. (2005) method a DMU was called efficient if its optimal upper bound efficiency obtained from model (5-2) is unity, i.e., $\left(\theta_{o}^{U^{*}}\right)_{\alpha}=1$.

\section{The proposed method}

The traditional DEA approach, which is a deterministic method, requires the values of inputs and outputs to be known exactly as single values. But, several DEA researchers argue that fuzzy DEA and interval DEA are more relevant in many practical situations due to the following reasons. The deterministic DEA scores are very sensitive to changes in data values or errors in the estimation of the efficient frontier. Quality differences in inputs and outputs among DMUs tend to distort the true efficiency performance evaluation (Hougaard, 1999). Furthermore, the inputs and outputs in DEA are often estimates rather than direct observations. For instance, the number of workers and the capital stock index calculated based on the perpetual inventory method are used as proxies of labor input and physical capital input, respectively (Khanjani Shiraz et al. 2016). The calculated efficiency scores are then regarded as approximations of the DMU's unknown capabilities (Hougaard, 1999). From a psychological point of view, Kao (2006) argues that interval measures are more acceptable to management because they would be reluctant to accept that their efficiency performance is no better than their competitors. In the present paper, we consider the framework for allowing for some or all of these circumstances.

For an illustration, let us consider LaPlante and Paradi's (2015) market model that investigates how bank branches should be operated relative to their regional market conditions. This model is developed to examine a branch's capability to utilize its existing resources and regional market conditions to produce new financial products and expand its market share. The market model contains variables such as the numbers of customers as an input and total lending and investment balances as outputs. The bank managers may have had difficulties in grasping the exact information regarding these forecasting variables. In this circumstance, the triangular membership function can be constructed using previous data information for predictions of center 
and left-hand and right-hand spread parameters. Our model can be applied even in the presence of missing data values, cf. Kao and Liu (2000).

Alternatively, the idea of risk-free and impossibility bounds can be incorporated as suggested by Triantis and Girod (1998) by the realistically attainable (i.e. conservative) values. For the bank branch problem, the risk-free bound for the lending and investment balances may then be estimated as the smallest value in the recent past. Since Triantis and Girod (1998) interpret an impossibility bound as the one that represents the most improbable production scenario, the associated bound can be obtained as the largest lending and investment balances. The bounds for the number of customers can be specified similarly.

The market model also includes non-discretionary (uncontrollable) environmental variables such as the local household income index and the number of competing branches in a $10 \mathrm{~km}$ radius. Our proposed model can easily include these non-discretionary variables. Hence, our model can provide useful information for relocation and closing of branches.

Now let us turn to the role of the multiplier bounds (known as $\varepsilon$ ) in DEA. Let us first clarify how they are traditionally implemented and their importance in fuzzy DEA. In standard DEA, Charnes and Cooper $(1984,1985)$ defined the "full [radial technical] efficiency" corresponding to Pareto-Koopmans efficiency by using the non-Archimedean scalar $\varepsilon$. However, there is another frequently employed notion associated with the Debreu-Farrell efficiency measure, whose associated notion is non-Pareto-Koopmans efficiency or so-called "weak [radial] efficiency". In the (dual) multiplier DEA model, some estimated multipliers might attain zero values because they are chosen in the assessed DMU's best possible light as is stated in the introduction. Hence, the projected efficient point on the boundary is Pareto-Koopmans inefficient with the corresponding Debreu-Farrell score being one. This is so because an input-output vector is Pareto-Koopmans efficient if and only if there exists a positive vector of multipliers. If one chooses $\varepsilon$ greater than a certain arbitrary real number, then the projection point may be outside the production possibility set. Therefore, the choice of $\varepsilon$ is very important in standard DEA. This also extends to fuzzy DEA, but its implementation has not been successful in the fuzzy DEA literature due to its computational complexity. Consequently, obtaining an appropriate $\varepsilon$ value is of great necessity so as to arrive at correct calculations, consistent estimates and, ultimately, to provide sound managerial insights. Indeed, the general adoption of fuzzy DEA in applications has been slower than expected from the number of published papers, partly because of a lack of 
attention to implementation details and reliable software packages. In the branch efficiency context above, resource misallocation potentially carried out by the bank relying on flawed analyses may lead to real financial losses. To avoid this kind of situation, the present study provides a procedure for specifying appropriate lower and upper bounds for $\varepsilon$. It should be noted that $\varepsilon$ is utilized as the coefficient of the supporting hyperplane (of the best-practice frontier) that contains the relevant facet associated to the assessed DMU.

In this section, we propose a four-step fuzzy DEA procedure for determining the lower bounds of input weights and outputs weights. We assume the same setting as above, transforming a set of strictly positive fuzzy data to interval data using the $\alpha$-level approach. The details of the proposed steps are presented below:

Step 1: We calculate the upper bound of the efficiency of all DMUs using model (5-2) from the optimistic viewpoint in which all DMUs are put in their best light to determine the efficiency of DMUs. It should be emphasized that the reference set derived at this step guarantees feasibility of model (5-2) as shown in Wang et al. (2005). $\mathrm{DMU}_{o}$ is said to be efficient if the best possible upper bound efficiency of $\mathrm{DMU}_{o}\left(\theta_{o}^{U^{*}}\right)_{\alpha}=1$, otherwise it is said to be inefficient. We denote the set of at least weakly efficient DMUs by $E^{+}$and the set of inefficient DMUs by $E^{-}$. The DMUs in class $E^{+}$can be either weakly or strongly efficient.

Step 2: We solve the primal fuzzy additive model (6) below for all DMUs with regards to Step 1 (the optimal value of the objective for model (5-2)) so as to identify four classifications for DMUs:

$$
\begin{aligned}
& \max \\
& \sum_{i=1}^{m} s_{i}^{+}+\sum_{r=1}^{s} s_{r}^{-} \\
\text {s.t. } & \sum_{j=1}^{n} \lambda_{j}\left(x_{i j}\right)_{\alpha}^{L}+s_{i}^{+}=\left(\theta_{o}^{U}\right)_{\alpha}^{*}\left(x_{i o}\right)_{\alpha}^{L}, i=1, \ldots, \mathrm{m}, \\
& \sum_{j=1}^{n} \lambda_{j}\left(y_{r j}\right)_{\alpha}^{U}-s_{r}^{-}=\left(\mathrm{y}_{r o}\right)_{\alpha}^{U}, r=1, \ldots, s, \\
& \lambda_{j} \geq 0, j=1, \ldots, n, \\
& s_{i}^{+}, s_{r}^{-} \geq 0, i=1, \ldots, m, r=1, \ldots, s .
\end{aligned}
$$


where $\left(\theta_{o}^{U}\right)_{\alpha}^{*}$ is the optimal solution of model (5-2) of $\mathrm{DMU}_{o}$ at $\alpha$, and $s_{i}^{+} \epsilon R^{m}$ and $s_{r}^{-} \epsilon R^{s}$ present the input excess and the output shortfall. The objective of model (6) is to find a solution that maximizes the sum of input excess and output shortfall while preserving $\left(\theta_{o}^{U}\right)_{\alpha}=\left(\theta_{o}^{U}\right)_{\alpha}^{*}$. Suppose that $\left(s_{i}^{+^{*}}, s_{r}^{-^{-*}}\right)$ is an optimal solution of model (6) at a given $\alpha$-level with the sum of input excess and output shortfall $s_{0}^{*}=\left(\sum_{i=1}^{m} s_{i}^{+^{*}}+\sum_{r=1}^{s} s_{r}^{-^{*}}\right)$. By means of $s_{0}^{*}$ and $\left(\theta_{o}^{U}\right)_{\alpha}^{*}$, we may then partition the DMUs into the sets $E, F, N E$ and $N F$ that are determined as follows:

- $\quad \mathrm{ADMU}_{o}$ is called $E$ if $\left(\theta_{o}^{U}\right)_{\alpha}^{*}=1$ and $s_{0}^{*}=0$.

- $\quad \mathrm{A} \mathrm{DMU}_{o}$ is called $F$ if $\left(\theta_{o}^{U}\right)_{\alpha}^{*}=1$ and $s_{0}^{*}>0$.

- $\quad \mathrm{A} \mathrm{DMU}_{o}$ is called $N E$ if $\left(\theta_{o}^{U}\right)_{\alpha}^{*}<1$ and $s_{0}^{*}=0$.

- $\quad \mathrm{A} \mathrm{DMU}_{o}$ is called $N F$ if $\left(\theta_{o}^{U}\right)_{\alpha}^{*}<1$ and $s_{0}^{*}>0$.

DMUs in sets $E$ and $F$ that are also termed strongly and weakly efficient DMUs establish the strongly and weakly efficient frontiers in the DEA model, respectively. DMUs in sets $N E$ and $N F$ are called inefficient DMUs. DMUs in sets $F$ and $N F$ have positive slacks while DMUs in sets $E$ and $N E$ have zero slacks. The cause of positive slacks for the DMUs in set $N F$ is that these units are being projected onto weak frontiers. Put differently, an inefficient DMU with non-zero slacks cannot be projected onto a full-dimensional efficient facet (FDEF).

Proposition 1: Model (6) is feasible and its optimal objective function value is non-negative and bounded.

Proof. See Appendix A.

Step 3: In the conventional CCR model, a full-dimensional efficient facet is derived from $m+s-1$ linear independent efficient DMUs that must be placed on the same facet. We determine the positive lower bounds for all dual input $\left(\varepsilon_{i}^{v}\right)$ and output weights $\left(\varepsilon_{r}^{u}\right)$ to perturb the weakly efficient frontiers using the SCSC solution for the strongly efficient DMUs. Mathematically speaking, based on the SCSC solution $u_{r}^{*}+s_{r}^{-^{*}}>0, u_{r}^{*} s_{r}^{-*}=0$ and $v_{i}^{*}+s_{i}^{+^{*}}>0, u_{i}^{*} s_{i}^{+^{*}}=0$. The application of SCSC is found in many DEA studies e.g., Charnes et al. (1991). 
We first maximize the sum of the input weights and output weights simultaneously for each strongly efficient $\mathrm{DMU}$, i.e., for all $D M U_{k} \in E$ for $k=1, \ldots, K$, that are identified in step 2 according to the technology from the optimistic viewpoint.

$$
\begin{aligned}
\max & \sum_{i=1}^{m} v_{i}+\sum_{r=1}^{s} u_{r} \\
\text { s.t. } & \sum_{i=1}^{m} v_{i}\left(x_{i k}\right)_{\alpha}^{L}=1, \\
& \sum_{r=1}^{s} u_{r}\left(y_{r k}\right)_{\alpha}^{U}=1, \\
& \sum_{r=1}^{s} u_{r}\left(y_{r j}\right)_{\alpha}^{U}-\sum_{i=1}^{m} v_{i}\left(x_{i j}\right)_{\alpha}^{L} \leq 0, j=1, \ldots, n, \\
& v_{i} \geq 0, i=1, \ldots, m ; u_{r} \geq 0, r=1, \ldots, s .
\end{aligned}
$$

Let $s_{i}^{+^{*}}, s_{r}^{-^{*}}, v_{i}^{*}$ and $u_{r}^{*}$ be an optimal solution for a strongly efficient DMU. If the optimal solution satisfies SCSC, $v_{i}^{*}$ and $u_{r}^{*}$ are positive. Therefore, we attempt to find the positive lower bound of input and output weights for each DMU in set $E$ such that the strongly efficient frontier keeps unchanged. We solve model (8) for DMUs in set $E$ (phase 1) and determine the positive optimal $v_{i}^{*}$ and $u_{r}^{*}$. Next (phase 2), we remove positive $v_{i}^{*}$ and $u_{r}^{*}$ from the objective function of model (8) and re-solve the model. We continue inductively to solve model (8) until at some phases the optimal value is zero, i.e., there does not exist $v_{i}^{*}$ and $u_{r}^{*}$ in the objective function of (8). As a result, the SCSC solution for $\mathrm{DMU}_{\mathrm{o}}$ is denoted by $\left(u_{r}^{o}, v_{i}^{o}\right)$. As shown in Charnes et al. (1991), an optimal solution $\left(u_{r}^{o}, v_{i}^{o}\right)$ for $\mathrm{DMU}_{\mathrm{o}}$ that satisfies SCSC is the average of all $\left(v_{i}^{*}, u_{r}^{*}\right)$ in each phase. Suppose that $\left(u_{r}^{k}, v_{i}^{k}\right)$ be SCSC solution for each $D M U_{k} \in E, k=1, \ldots, K$. The lower bounds of input weights $\left(\varepsilon_{i}^{v}\right)$ and output weights $\left(\varepsilon_{r}^{u}\right)$ can be obtained as:

$$
\begin{aligned}
\varepsilon_{i}^{v} & =\min _{k=1, \ldots, K}\left\{v_{i}^{k}\right\} \\
\varepsilon_{r}^{u} & =\min _{k=1, \ldots, K}\left\{u_{r}^{k}\right\}
\end{aligned}
$$

Proposition 2: Model (8) is feasible and its optimal objective function value is non-negative and bounded.

Proof. See Appendix $B$. 
Step 4: We re-calculate the efficiency score of DMUs in sets $F$ and $N F$ using model (5-2) in terms of perturbing the weakly efficient frontier by defined $\varepsilon_{i}^{v}$ and $\varepsilon_{r}^{u}$ for sets $I$ and $R$, respectively, where

$I=\left\{i \mid x_{i j}\right.$ has positive slack value, $D M U_{j} \in F$ or $\left.N F\right\}$ and

$R=\left\{r \mid y_{r j}\right.$ has positive slack value, $D M U_{j} \in F$ or $\left.N F\right\}$.

In other words, we consider $v_{i} \geq \varepsilon_{i}^{v}, i \in I$ and $u_{r} \geq \varepsilon_{r}^{u}, r \in R$ as the lower bounds of input and output weights in calculating the efficiency of DMUs in set $F$ and $N F$.

The four-step procedure of the proposed method is summarized in Figure 1. In line with describing the steps of Figure 1, we also outline the computational complexity of the proposed procedure by counting the number of calculations in each step for each $\alpha$-level:

- Step 1 requires solving model (5-2) $n$ times where $n$ is the number of DMUs for calculating the upper efficiency of all the DMUs. It should be noted that the degree of fuzziness (or crispiness) adds information about the degree of uncertainty and our proposed fuzzy DEA model has this feature.

- Step 2 requires solving model (6) $n$ times for determining the $E, F, N E$ and $N F$ classes.

- Step 3 first requires solving model (8) $|E|$ times where $|E|$ is the cardinality of set $E$, then proceeds with solving model (8) up to its optimal objective function value turns into zero for calculating the lower bounds of input weights $\left(\varepsilon_{i}^{v}\right)$ and output weights $\left(\varepsilon_{r}^{u}\right)$.

- Step 4 requires solving model (5-2) $|F|+|N F|$ times in the presence of $\varepsilon_{i}^{v}$ and $\varepsilon_{r}^{u}$ where $|F|$ and $|N F|$ are the cardinalities of sets $F$ and $N F$, respectively, for re-calculating the upper efficiency of the DMUs in sets $F$ and $N F$.

\section{---------Insert Figure 1 about here-----------}

Corollary 1. If $\mathrm{DMU}_{\mathrm{o}}$ belongs to sets $E$ or $N E$, then its efficiency score keeps unchanged with lower bounds of $\varepsilon_{r}^{u}$ and $\varepsilon_{i}^{v}$. 
Corollary 2. If $\mathrm{DMU}_{\mathrm{o}}$ belongs to sets $F$ or $N F$, then its efficiency score will be changed after employing the lower bounds of $\varepsilon_{r}^{u}$ and $\varepsilon_{i}^{v}$.

\section{Comparison with Khoshfetrat and Daneshvar (2011)}

Khoshfetrat and Daneshvar (2011) propose a method with claims similar to ours, making it a natural point of comparison. However, as we show below by means of three propositions and a counterexample, their method is flawed and does not produce the alleged results. We end this section with a constructive remark to partially correct their model.

Assume that there are $n$ DMUs within a set of observations where each observation transforms $m$ strictly positive ${ }^{8}$ fuzzy inputs, $\tilde{x}_{i j}, i=1, \ldots, m ; j=1, \ldots, n$ into $s$ strictly positive fuzzy outputs, $\tilde{y}_{r j}, r=1, \ldots, s ; j=1, \ldots, n$. The fuzzy input-output set is transformed to interval data using the $\alpha$ level approach. The Khoshfetrat and Daneshvar (2011) method can be summarized as follows:

Step 1: Calculate the upper efficiency of the DMUs using model (4-2) to determine the DMUs that are classified in the either $E^{+}$or $E^{-}$group.

Step 2: Solve the primal fuzzy additive model $(9)^{9}$ for DMUs in class $E^{+}$with respect to the optimistic viewpoint in order to specify a set of the weakly efficient DMUs, viz.:

$$
\begin{array}{ll}
\min & -\left(\sum_{i=1}^{m} s_{i}^{+}+\sum_{r=1}^{s} s_{r}^{-}\right) \\
\text {s.t. } & \left(x_{i o}\right)_{\alpha}^{L}-\sum_{j=1}^{n} \lambda_{j}\left(x_{i j}\right)_{\alpha}^{U}-s_{i}^{+}=0, \quad i=1, \ldots, m, \\
& \left(y_{r o}\right)_{\alpha}^{U}-\sum_{j=1}^{n} \lambda_{j}\left(y_{r j}\right)_{\alpha}^{L}+s_{r}^{-}=0, \quad r=1, \ldots, s, \\
& s_{i}^{+} \geq 0, \quad i=1, \ldots, m ; \quad s_{r}^{-} \geq 0, r=1, \ldots, s, \\
& \lambda_{j} \geq 0, \quad j=1, \ldots, n .
\end{array}
$$

$\mathrm{DMU}_{o}$ in $E^{+}$is called weakly efficient if the optimal value of (9) has a positive solution. The set of the weakly efficient DMUs is denoted by $S$.

\footnotetext{
${ }^{8}$ It is assumed by Khoshfetrat and Daneshvar (2011, p.340).

${ }^{9}$ Technically speaking, it is Phase II of the conventional DEA that maximizes the sum of input excesses and output shortfalls.
} 
Step 3: Calculate lower bounds for all dual input weights $\left(\varepsilon_{i}^{v}\right)$ and output weights $\left(\varepsilon_{r}^{u}\right)$ to perturb the efficient frontiers. The two following models with the identical constraints and different objective functions $\left(\max v_{i}\right.$ and $\left.\max u_{r}\right)$ are solved for all $v_{i}(i=1, \ldots, m)$ and $u_{r}($ $r=1, \ldots, s)$ belonging to the set of weakly efficient peers $(S)$ :

$$
\begin{array}{ll}
\max & v_{i}\left(\max u_{r}\right) \\
\text { s.t. } & \sum_{i=1}^{m} v_{i}\left(x_{i o}\right)_{\alpha}^{L}=1, \\
& \sum_{r=1}^{s} u_{r}\left(y_{r j}\right)_{\alpha}^{L}-\sum_{i=1}^{m} v_{i}\left(x_{i j}\right)_{\alpha}^{U} \leq 0, j=1, \ldots, n, \\
& v_{i} \geq 0, i=1, \ldots, m ; \quad u_{r} \geq 0, r=1, \ldots, s .
\end{array}
$$

Suppose that $v_{i}^{*},(i=1, \ldots, m)$ and $u_{r}^{*},(\mathrm{r}=1, \ldots, \mathrm{s})$ are the optimal solutions of the above models. Then, the lower bounds for the dual input weights $\left(\varepsilon_{i}^{v}\right)$ and output weights $\left(\varepsilon_{r}^{u}\right)$ are defined as: $\varepsilon_{r}^{u}=\min \left\{u_{r}^{*} \mid D M U_{o} \in S\right\}, r=1, \ldots, s$, $\varepsilon_{i}^{v}=\min \left\{v_{i}^{*} \mid D M U_{o} \in S\right\}, i=1, \ldots, m$.

Step 4: Calculate the upper bound of the efficiency scores for all the DMUs using the modified model (4-2) by consideration of the lower bounds of weights as:

$$
v_{i} \geq \varepsilon_{i}^{v},(i=1, \ldots, m), u_{r} \geq \varepsilon_{r}^{u},(r=1, \ldots, s) .
$$

Let us present the shortcomings of Khoshfetrat and Daneshvar (2011) by means of three propositions:

Proposition 3: Model (9) has no feasible solution for DMUs in class $E^{+}$.

\section{Proof. See Appendix $C$.}

For more clarification, consider a small example with three DMUs, one interval input and one interval output. Three units, $\mathrm{DMU}_{\mathrm{A}}, \mathrm{DMU}_{\mathrm{B}}$ and $\mathrm{DMU}_{\mathrm{C}}$, produce interval output $[5,6],[2,4]$ and $[3,4]$ using interval input [2, 4], [2, 4] and [6, 8], respectively, depicted in Figure 2. In Khoshfetrat and Daneshvar (2011)'s method, the data set $(4,5),(4,2)$ and $(8,3)^{10}$ associated with $\mathrm{DMU}_{\mathrm{A}}, \mathrm{DMU}_{\mathrm{B}}$ and $\mathrm{DMU} \mathrm{C}_{\mathrm{C}}$ is considered to determine the efficient frontier denoted by the radial line $\mathrm{T}_{\mathrm{c}}(1)$ in Figure 2. When evaluating $\mathrm{DMU}_{\mathrm{A}}$ and $\mathrm{DMU}_{\mathrm{B}}$ using model (9), their optimal

\footnotetext{
${ }^{10}$ The first and second components of $(x, y)$ represent $x$ - and $y$ - axes.
} 
solutions, i.e., $(2,6)$ and $(2,4)$, touch the hull of the technology defined by the $\mathrm{T}_{\mathrm{c}}(1)$ frontier. This explains why model (9) is infeasible for $\mathrm{DMU}_{\mathrm{A}}$ and $\mathrm{DMU}_{\mathrm{B}}$ and why $\mathrm{DMU}_{\mathrm{C}}$ is the only feasible alternative in the method of Khoshfetrat and Daneshvar (2011). In addition, we note that the $\mathrm{T}_{\mathrm{c}}(2)$ hull is the frontier created by the technology of Despotis and Smirlis (2002) for evaluating $\mathrm{DMU}_{\mathrm{B}}$ while the technology of Wang et al. (2005) is constructed by the $\mathrm{T}_{\mathrm{c}}(3)$ frontier for evaluating all DMUs.

\section{----------Insert Figure 2 about here----------}

Proposition 4: Model (9) has feasible solutions for DMUs in class $E^{-}$.

\section{Proof. See Appendix $D$}

The results in Propositions 3 and 4 are in direct contradiction with the claim by Khoshfetrat and Daneshvar (2011, p.342) "that the above LP model [(9)] is infeasible if $\mathrm{DMU}_{\mathrm{o}}$ be (sic!) inefficient.". Since model (9) is used as the first step in the algorithm, the subsequent steps are performed on an incomplete reference set and the resulting order in Khoshfetrat and Daneshvar (2011) is then incorrect with respect to the full reference set.

The numerical example in Khoshfetrat and Daneshvar (2011, p.343) is accompanied by the statement that "we notice that in $\alpha=0.25$ all of the DMUs $A, B, C, F, G$ and $H$ are weak[ly] efficient. So for DMUs $C, F$ and $H$ we have: $\theta^{*}=1$ and at least one of the $v_{i}$ and $u_{r}$ should be zero. Hence these DMUs are belonging to $S^{\prime \prime}$. Since the infeasibility applies for or all DMUs in $E^{+}$, this result cannot have been obtained by the Khoshfetrat and Daneshvar (2011) method as described.

Proposition 5: The application of Step 4 in Khoshfetrat and Daneshvar (2011) may yield infeasible solutions.

\section{Proof. See Appendix E.}

The impact of Proposition 5 is crucial, as it may lead to fruitless applications by practioners, trying to obtain solutions through a non-converging process. However, Khoshfetrat and Daneshvar (2011, p.344, Table 4) erroneously reported a result that cannot be the result of the algorithm. The intuition behind Proposition 5 draws on classical results in convex analysis or multi-objective programming, where the Pareto-optimal set is characterized by projections towards an exterior point (ideal) or from an interior point (nadir), but not through a fullydimensional constrained solution. 
Finally, the two models (10) in Step (3) of the Khoshfetrat and Daneshvar (2011) method contain an error in the input correspondence. To create these models the best situation for $\mathrm{DMU}_{\mathrm{o}}$ and the worst situation for $\mathrm{DMU}_{j}(j \neq o)$ (i.e., the optimistic scenario) must be used (similar to models (4-2)) whereas models (8) take the worst situation for all the DMUs into account for calculating the maximum of the weights. In other words, the worst light of DMUs, $\left(y_{r j}\right)_{\alpha}^{L}$ and $\left(x_{i j}\right)_{\alpha}^{U}$, are used in models (10) to build the production set while $\mathrm{DMU}_{o}$ considers $\left(x_{i o}\right)_{\alpha}^{L}$ that may violate the convex production set. The correct models, instead of models (10) that maximize input and output weights should be formulated as follows:

$\max u_{r}\left(\max u_{r}\right)$

$$
\begin{aligned}
& \text { s.t. } \sum_{i=1}^{m} v_{i}\left(x_{i o}\right)_{\alpha}^{L}=1, \\
& \sum_{r=1}^{s} u_{r}\left(y_{r o}\right)_{\alpha}^{U}-\sum_{i=1}^{m} v_{i}\left(x_{i o}\right)_{\alpha}^{L} \leq 0, \\
& \sum_{r=1}^{s} u_{r}\left(y_{r j}\right)_{\alpha}^{L}-\sum_{i=1}^{m} v_{i}\left(x_{i j}\right)_{\alpha}^{U} \leq 0, j=1, \ldots, n, j \neq o, \\
& v_{i} \geq 0, u_{r} \geq 0 . \quad i=1, \ldots, m ; r=1, \ldots, s .
\end{aligned}
$$

\section{Numerical example}

In this section, we present a numerical example to illustrate the proposed approach for determining the lower bounds of input and outputs weights in order to re-evaluate the weakly efficient DMUs appropriately. Consider a hypothetical bank having eight new branches, evaluated by means of one crisp input and two fuzzy outputs as presented in Table 1 . The input is the size of branch office (in square meters) as a proxy for fixed resource allocation, without strategic and planning relevance. The two fuzzy outputs are budgeted (future) total lending demand (output 1) and (future) total demand for investment funds (output 2). The bank management would like to set a target for each branch in order to reconstruct the branch network based on the local budgets. However, the outputs in the next period are not estimated precisely and are considered as fuzzy outputs. 
In the face of uncertainty, the $\alpha$-cut concept is one of the key properties in fuzzy set theory providing a link between fuzzy and crisp functions (Klir \& Yuan, 1995; Klir \& Smith, 2001). The bank management decides to apply the $\alpha$-cut method to deal with the imprecision associated with the outputs. The possibility level $\alpha$, signifying the degree of uncertainty, takes a value between 0 and 1 . For example, $\alpha=0, \alpha=0.5$, and $\alpha=1$ represent the managers' pessimistic, moderate, and optimistic views, respectively, regarding the future outputs. Adding two inbetween values of $\alpha=0.25$ and $\alpha=0.75$, we estimate efficiency scores based on our method and obtain a table for managerial estimates with respect to different $\alpha$ values. The table corresponding to various degrees of uncertainty can be used to graph the efficiency of the new branches as a function of the 'optimism' $\alpha$. Note that the $\alpha$ value does not affect the crisp input data. In this example, the proposed four-step method is applied based on the $\alpha$-cut concept to solve this problem and the computational procedure is summarized as follows:

Step 1: After applying the $\alpha$-level method to fuzzy data for five levels $\{0,0.25,0.50,0.75,1\}$, the corresponding data revealed as reported in Table 2. The upper bounds of the efficiency of all the DMUs are calculated using model (5-2) at distinct $\alpha$-levels to identify the set of the efficient DMUs as shown in the Table $3^{11}$. Therefore, Step 1 requires solving model (5-2) $8 * 5=40$ times where 8 and 5 represent the number of DMUs and $\alpha$-levels, respectively for obtaining the upper efficiency of all DMUs. For instance, let us consider $\alpha=0.50$. From Table 3, $\mathrm{DMU}_{2}, \mathrm{DMU}_{3}$, $\mathrm{DMU}_{4}, \mathrm{DMU}_{5}, \mathrm{DMU}_{7}$ and $\mathrm{DMU}_{8}$ are efficient DMUs since their upper bounds are equal to unity and other DMUs are inefficient. The production frontier for $\alpha=0.50$ is depicted using the black dashed line in Figure 3. To create this line, we use the best light of DMUs that are shown by the red bullets. We now need to classify the DMUs by means of the next step.

\section{----------Insert Tables 2 and 3 about here----------- \\ ---------Insert Figure 3 about here-----------}

Step 2: To identify the classification of DMUs, we solve model (6) for all the DMUs determined in the previous step. The results in Table 4 indicate that there is no weakly efficient DMU for

\footnotetext{
${ }^{11}$ To solve the mathematical models, we use General Algebraic Modeling System (GAMS) software and the pertinent code involving solving models (5-2), (6) and (8) for five different $\alpha$-levels are appended as Appendix $D$. It is performed on a laptop computer with an Intel Core i7 CPU $2.80 \mathrm{GHz}$ and 8-GB RAM. The elapsed time for solving all the models is 31 seconds.
} 
$\alpha=\{0,0.25\}$ and that set $F$ consequently is empty. From Table 5, DMUs in $N F$ are determined for $\{0,0.25,0.50,0.75,1\}$. We can accordingly classify the DMUs into sets $E, F, N E$ and $N F$ for a specific $\alpha$. Therefore, we solve model (6) 8*5=40 times in Step 2 where 8 and 5 represent the number of DMUs and $\alpha$-levels, respectively, to determine the $E, F, N E$ and $N F$ classes. For instance, let us consider $\alpha=0.50 . \mathrm{DMU}_{3}, \mathrm{DMU}_{4}$ and $\mathrm{DMU}_{5}$ are the strongly efficient DMUs (i.e., $E=\{3,4,5\}), \mathrm{DMU}_{7}$ and $\mathrm{DMU}_{8}$ are weakly efficient DMUs (i.e., $F=\{7,8\}$ ), DMU 1 and $\mathrm{DMU}_{6}$ belong to sets $N E$ and $N F$, respectively (i.e., $N E=\{1\}$ and $N F=\{6\}$ ).

\section{---------Insert Tables 4 and 5 about here-----------}

Step 3: To compute the lower bounds of all input weights $\left(\varepsilon_{i}^{v}\right)$ and output weights $\left(\varepsilon_{r}^{u}\right)$, we first use model (8) at different $\alpha$-levels $\{0,0.25,0.5,0.75,1\}$ for the strongly efficient DMUs (determined in Step 2) and we then employ the proposed approach. Table 6 reports the values of $\varepsilon_{i}^{v}$ and $\varepsilon_{r}^{u}$. Note that it is necessary to solve model (8) $4+4+3+4+3=18$ times where $4,4,3,4$ and 3 indicate the number of runs regarding the $0.00,0.25,0.50,0.75$ and 1.00 levels, respectively, to calculate the lower bounds of one input and two output weights $\varepsilon_{1}^{v}, \varepsilon_{1}^{u}$ and $\varepsilon_{2}^{u}$ for each $\alpha$-level.

\section{----------Insert Table 6 about here-----.-----}

Step 4: The upper bounds of the efficiency scores of DMUs in sets $F$ and $N F$ are re-assessed along with the lower bounds of the weights calculated in step 3. The results are reported in Table 7. Notably, the efficiency scores of DMUs in sets $E$ and $N E$ are unchanged as Corollary 1 states, while the efficiency scores of DMUs in sets $F$ and $N F$ are modified based on defining some hypothetical efficient facets. This step solves model (5-2) $|F|+|N F|$ times in the presence of $\varepsilon_{i}^{v}$ and $\varepsilon_{i}^{u}$ with the aim of re-calculating the upper efficiency of DMUs in sets $F$ and $N F$ Therefore, in this particular case, model (5-2) is run in total 14 times.

\section{----------Insert Table 7 about here-----------}

Hence, the proposed method in this paper is capable of determining the lower bounds of input weights and outputs weights in order to re-evaluate the DMUs in sets $F$ and $N F$. In other words, we slightly rotate the weak frontier hyperplanes from the appropriate extreme efficient DMUs for the purpose of more precise evaluation in the fuzzy environment. 


\section{Concluding remarks}

The problem of characterizing the non-Archimedean constant $\varepsilon$ is far from a trivial consequence of numerical implementations of efficiency projections. Already in a conventional setting with a production possibility set as a subspace of the real hyper cone, the widely used radial DEA-CCR model is unable to distinguish between weakly and strongly efficient observations. Intuitive solutions such as imposing a numerical value for $\varepsilon$ are far from harmless, as shown by Ali and Seiford (1993) and Thanassoulis and Allen (1998). Indeed, this implies through duality a weight restriction that changes the production possibility set for projections and the resulting scores. The problems of characterizing the frontier are exacerbated in the presence of imprecise or fuzzy data. When the production possibility set is no longer well-defined, paradoxically an even more stringent approach is called for to characterize the observations, to achieve a reasonable level of discrimination and to correctly estimate radial projections in the space. Given that a projection of a fuzzy set yields a distribution for the efficiency, rather than a point estimate, an ad hoc approach relying upon the direct utilization of slack variables is conceptually complex and vague. This paper proposes a new four-stage procedure for re-shaping the weakly efficient frontiers in a fuzzy production possibility set by introduction of the non-Archimedean infinitesimal $\varepsilon$ as a lower bound for the dual weights. Infeasibility and violation of preserving the extreme efficient DMUs are the most frequent problems in imposing lower bound for the dual weights in the conventional DEA models. Our method guarantees feasibility in the presence of the lower dual weight bounds along with keeping the original strongly efficient frontier when input-output data are characterized by fuzzy numbers. Our detailed review of a seemingly related paper, Khoshfetrat and Daneshvar (2011), reveals a number of serious flaws that our method addresses.

Imprecise data applications are particularly interesting for further work and can be considered as generalizations of the conventional crisp production spaces. We note here that the literature on the directional distance functions in Chambers et al.'s $(1996,1998)$ relating to the radial projection have not been fully exploited for imprecise data. Another related stream generalizes the convexity property over the production set into local and global semi-convex subsets as in Agrell et al. (2005). In this regard, it may also be interesting to anchor the current framework in the axiomatic approach of Podinovski and Kousmanen (2011) for non-convex production spaces with weak disposability. 
Finally and not least, comparative analyses on real data with intuitive interpretations would be interesting to contrast and validate the relative merits of the family of fuzzy DEA models with that of conventional approaches using mean values. The contribution in this paper is one step towards a both conceptually sound and numerically stable implementation of the former approaches.

\section{References}

Agrell, P. J., \& Niknazar, P. (2014). Structural and behavioral robustness in applied best-practice regulation. Socio-Economic Planning Sciences, 48(1), 89-103.

Agrell, P. J., Bogetoft, P., Brock, M., \& Tind, J. (2005). Efficiency evaluation with convex pairs. Advanced Modeling and Optimization, 7(2), 211-237.

Ali, A.I., \& Seiford, L.M. (1993). Computational accuracy and infinitesimals in data envelopment analysis. INFOR, 31(4), 290.

Alirezaee, M.R. (2005). The overall assurance interval for the non-Archimedean Epsilon in DEA models; a partition base algorithm. Applied Mathematics and Computation, 164, 667-674.

Alirezaee, M.R., \& Khalili, M. (2006). Recognizing the efficiency, weak efficiency and inefficiency of DMUs with an epsilon independent linear program. Applied Mathematics and Computation, 183, 1323-1327.

Allen, A.R., \& Thanassoulis, E. (2004). Improving envelopment in data envelopment analysis. European Journal of Operational Research, 154, 363-379.

Amin, G.R., \& Toloo, M. (2004). A polynomial-time algorithm for finding Epsilon in DEA models. Computers and Operations Research, 31(5), 803-805.

Bammer, G., \& Smithson, M. (Eds.), 2008. Uncertainty and Risk: Multidisciplinary Perspectives. Earthscan Risk in Society Series. Earthscan, London, UK.

Bessent, A., Bessent, W., Elam, J., \& Clark, T., (1988). Efficiency frontier determination by constrained facet analysis. Operations Research, 36 (5), 785-796.

Chambers, R.G., Chung, Y., \& Färe, R. (1996). Benefit and distance functions. Journal of Economic Theory, 70(2), 407-419.

Chambers, R.G., Chung, Y., \& Färe, R. (1998). Profit, directional distance functions and Nerlovian efficiency. Journal of Optimization Theory and Applications, 98(2), 351-364. 
Charnes, A., \& Cooper, W.W. (1984). A non-Archimedian CCR ratio for efficiency analysis: a rejoinder to Boyd and Färe, European Journal of Operation Research, 15, 333-334.

Charnes, A., Cooper, W. W., \& Rhodes, E. (1978). Measuring the efficiency of decision making units. European Journal of Operational Research, 2 (6), 429-444.

Charnes, A., Cooper, W.W., \& Rhodes, E. (1979). Short communication: measuring the efficiency of decision making units. European Journal of Operation Research, 3, 339.

Charnes, A., Cooper, W.W., \& Thrall R.M. (1991). A structure for classifying and charactering efficiency and inefficiency in data envelopment analysis, Journal of Productivity Analysis, 2(2), 197-237.

Chen, Y., Morita, H., \& Zhu, J. (2003). An approach for determining DEA efficiency bounds. In Multi-Objective Programming and Goal Programming, (pp. 105-110). Springer Berlin Heidelberg.

Cooper, W.W., Park, K.S., \& Yu, G. (1999). IDEA and AR-IDEA: models for dealing with imprecise data in DEA. Management Science, 45, 597-607.

Cooper, W.W., Seiford, L.M, \& Tone, K. (2002). Data envelopment analysis a comprehensive text with models, applications, references and DEA solved software. Springer Science \& Business Media.

Despotis, D.K., \& Smirlis, Y.G., (2002). Data envelopment analysis with imprecise data. European Journal of Operational Research, 140, 24-36.

Emrouznejad, A., \& Amin, G.R. (2009). DEA models for ratio data: convexity consideration. Applied Mathematical Modelling, 33(1), 486-498.

Emrouznejad, A., Rostamy-Malkhalifeh, M., Hatami-Marbini, A., \& Tavana, M. (2012). General and multiplicative non-parametric corporate performance models with interval ratio data. Applied Mathematical Modelling, 36, 5506-5514.

Emrouznejad, A., Rostamy-Malkhalifeh, M., Hatami-Marbini, A., Tavana, M., \& Aghayi, N. (2011). An overall profit Malmquist productivity index with fuzzy and interval data. Mathematical and Computer Modelling, 54, 2827-2838.

Emrouznejad, A., Tavana, \& M., Hatami-Marbini, A. (2014). The state of the art in fuzzy data envelopment analysis, In Performance measurement with fuzzy data envelopment analysis (pp. 1-45). Springer Berlin Heidelberg. 
Green, R.H., Doyle, J.R., \& Cook, W.D., (1996). Efficiency bounds in data envelopment analysis. European Journal of Operational Research, 89, 482-490.

Guo, P., \& Tanaka, H. (2001). Fuzzy DEA: A perceptual evaluation method. Fuzzy Sets and Systems, 119, 149-160.

Hatami-Marbini, A., \& Saati, S. (2009). Stability of RTS of efficient DMUs in DEA with fuzzy under fuzzy data. Applied Mathematical Sciences, 3, 2157-2166.

Hatami-Marbini, A., Emrouznejad, A., \& Tavana, M. (2011). A taxonomy and review of the fuzzy data envelopment analysis literature: two decades in the making. European Journal of Operational Research, 214, 457-472.

Hatami-Marbini, A., Tavana, M., Saati, S., \& Agrell, P.J. (2013). Positive and normative use of fuzzy DEA - BCC models: A critical view on NATO enlargement. International Transactions in Operational Research, 20(3), 411-433.

Hougaard, J.L. (1999). Fuzzy scores of technical efficiency. European Journal of Operational Research, 115(3), 529-541.

Ignatius, J., Ghasemi, M. R., Zhang, F., Emrouznejad, A., \& Hatami-Marbini, A. (2016). Carbon efficiency evaluation: An analytical framework using fuzzy DEA. European Journal of Operational Research, 253(2), 428-440.

Jahanshahloo, G.R., \& Khodabakhshi, M. (2004). Determining assurance interval for nonArchimedean element in the improving outputs model in DEA. Applied Mathematics and Computation, 151 (2), 501-506.

Kao, C. (2006). Interval efficiency measures in data envelopment analysis with imprecise data. European Journal of Operational Research, 174(2), 1087-1099.

Kao, C., \& Liu, S.T. (2000). Data envelopment analysis with missing data: an application to university libraries in Taiwan. Journal of the Operational Research Society, 897-905.

Kaufmann, A., \& Gupta, M.M. (1991). Introduction to fuzzy arithmetic theory and applications, Van Nostrand Reinhold, New York.

Khanjani Shiraz, R. K., Fukuyama, H., Tavana, M., \& Di Caprio, D. (2016). An integrated data envelopment analysis and free disposal hull framework for cost-efficiency measurement using rough sets. Applied Soft Computing, 46, 204-219.

Khoshfetrat, S., \& Daneshvar, S. (2011). Improving weak efficiency frontiers in the fuzzy data envelopment analysis models. Applied Mathematical Modelling, 35, 339-345. 
Klir, G.J. (1987). Where do we stand on measures of uncertainty, ambiguity, fuzziness, and the like?. Fuzzy sets and systems, 24(2), 141-160.

Klir, G.J., \& Smith, R.M. (2001). On measuring uncertainty and uncertainty-based information: recent developments. Annals of Mathematics and Artificial Intelligence, 32(1-4), 5-33.

Klir, G.J., \& Yuan B. (1995). Fuzzy sets and fuzzy logic: Theory and applications, New Jersey: Prentice Hall.

Kruse, R., \& Meyer, K.D. Statistics with Vague Data, volume 33. Reidel, Dordrecht, 1987.

Land, K. C., Lovell, C. A., \& Thore, S. (1993). Chance- constrained data envelopment analysis. Managerial and Decision Economics, 14(6), 541-554.

LaPlante, A.E., \& Paradi, J.C. (2015). Evaluation of bank branch growth potential using data envelopment analysis. Omega, 52, 33-41.

Lertworasirikul, S., Fang, S. C., Joines, J.A., \& Nuttle, H.L.W. (2003). Fuzzy data envelopment analysis (DEA): A possibility approach. Fuzzy Sets and Systems, 139, 379-394.

Mehrabian, S., Jahanshahloo, G.R., Alirezaee, M.R., \& Amin, G.R. (2000). An assurance interval for the non-Archimedean epsilon in DEA models. Operations Research, 48, 344-347.

Olesen, O. B., \& Petersen, N.C. (1995). Chance constrained efficiency evaluation. Management Science, 41(3), 442-457.

Olesen, O.B., \& Petersen, N.C. (2009). Target and technical efficiency in DEA-controlling for Environmental characteristics. Journal of Productivity Analysis, 32(1): 27-40.

Olesen, O.B., Petersen, N.C., \& Podinovski, V.V. (2015). Efficiency analysis with ratio measures. European Journal of Operational Research.

Podinovski, V.V., \& Kuosmanen, T. (2011). Modelling weak disposability in data envelopment analysis under relaxed convexity assumptions. European Journal of Operational Research, 211(3), 577-585.

Qin, R., Liu, Y., Liu, Z., \& Wang, G. (2009). Modeling fuzzy DEA with Type-2 fuzzy variable coefficients. In Advances in Neural Networks-ISNN 2009 (pp. 25-34). Springer Berlin Heidelberg.

Seaver, B., Triantis, K., \& Hoopes, B.J. (2004). Efficiency performance and dominance in influential subsets: an evaluation using fuzzy clustering and pair-wise dominance. Journal of Productivity Analysis, 21(2), 201-220. 
Sengupta, J.K. (1992). A fuzzy systems approach in data envelopment analysis. Computers \& Mathematics with Applications, 24(8), 259-266.

Shokouhi, A.H., Hatami-Marbini, A., Tavana, M., \& Saati, S. (2010). A robust optimization approach for imprecise data envelopment analysis. Computers \& Industrial Engineering, 59 (3), 387-397.

Shokouhi, A.H., Shahriari, H., Agrell, P.J., \& Hatami-Marbini, A. (2014). Consistent and robust ranking in imprecise data envelopment analysis under perturbations of random subsets of data. OR Spectrum, 36 (1), 133-160.

Simar, L., \& Wilson, P.W. (2000). A general methodology for bootstrapping in non-parametric frontier models. Journal of applied statistics, 27(6), 779-802.

Thanassoulis, E., \& Allen, R. (1998). Simulating weights restrictions in data envelopment analysis by means of unobserved DMUs. Management Science, 44 (4): 586-594.

Triantis, K. P. (2011). Engineering applications of data envelopment analysis. In Handbook on Data Envelopment Analysis (pp. 363-402). Springer US.

Triantis, K., \& Eeckaut, P.V. (2000). Fuzzy pair-wise dominance and implications for technical efficiency performance assessment. Journal of Productivity Analysis, 13(3), 207-230.

Triantis, K., \& Girod, O. (1998). A mathematical programming approach for measuring technical efficiency in a fuzzy environment. Journal of Productivity Analysis, 10(1), 85-102.

Triantis, K., Sarangi, S., \& Kuchta, D. (2003). Fuzzy pair-wise dominance and fuzzy indices: an evaluation of productive performance. European Journal of operational research, 144(2), 412-428.

Viertl, R. Statistical Methods for Non-Precise Data. CRC Press, Boca Raton, 1996.

Wang, Y. M., Luo, Y., \& Liang, L. (2009). Fuzzy data envelopment analysis based upon fuzzy arithmetic with an application to performance assessment of manufacturing enterprises. Expert systems with applications, 36(3), 5205-5211.

Wang, Y.M., Greatbanks, R., \& Yang, J., (2005). Interval efficiency assessment using data envelopment analysis. Fuzzy Sets and Systems, 153, 347-370.

Zadeh, L. A. (1979). A theory of approximate reasoning. Machine intelligence, 9, 149-194.

Zadeh, L.A. (1965). Fuzzy sets, Information and Control, 8:338-353.

Zimmermann, H.-J. (1987). Fuzzy Set, Decision Making and Expert System, Kluwer Academic Publishers, Boston. 
Zimmermann, H.J. (1996). Fuzzy sets theory-and its applications, Springer Science \& Business Media. 


\section{Appendix A}

\section{Proof of Proposition 1}

(i) Feasibility of model (6):

Let us consider the following envelopment model that is evaluated the upper bound of $\mathrm{DMU}_{o}$ :

$\min \left(\theta_{o}^{U}\right)_{\alpha}$

s.t. $\sum_{j=1}^{n} \lambda_{j}\left(x_{i j}\right)_{\alpha}^{L} \leq\left(\theta_{o}^{U}\right)_{\alpha}\left(x_{i o}\right)_{\alpha}^{L}, i=1, \ldots, \mathrm{m}$,

$\sum_{j=1}^{n} \lambda_{j}\left(y_{r j}\right)_{\alpha}^{U} \geq\left(\mathrm{y}_{r o}\right)_{\alpha}^{U}, r=1, \ldots, s$

$\lambda_{j} \geq 0, j=1, \ldots, n$.

where $\left(\theta_{o}^{U}\right)_{\alpha}$ and $\lambda_{j}=0, j=1, \ldots, n$, are the decision variables at $\alpha$. The above model has at least one feasible solution as follows:

$\left(\theta_{o}^{U}\right)_{\alpha}=1$,

$\lambda_{o}=1$,

$\lambda_{j}=0, \quad j=1, \ldots, n, j \neq o$.

Hence, model (7) always has a feasible solution. If $\left(\left(\theta_{o}^{U}\right)_{\alpha}^{*}, \lambda_{j}^{*}\right), j=1, \ldots, n$, is an optimal solution of (7) for $\mathrm{DMU}_{o}$, the inequality constraints of model (7) can be transformed into the following equality form:

$$
\begin{array}{ll}
s_{i}^{+}=\left(\theta_{o}^{U}\right)_{\alpha}^{*}\left(x_{i o}\right)_{\alpha}^{L}-\sum_{j=1}^{n} \lambda_{j}^{*}\left(x_{i j}\right)_{\alpha}^{L}, & i=1, \ldots, \mathrm{m}, \\
s_{r}^{-}=\sum_{j=1}^{n} \lambda_{j}^{*}\left(y_{r j}\right)_{\alpha}^{U}-\left(\mathrm{y}_{r o}\right)_{\alpha}^{U}, & r=1, \ldots, s,
\end{array}
$$

Obviously, the above constraints are the same as the constraints of model (6) when $\lambda_{j}=\lambda_{j}^{*}, \quad j=1, \ldots, n$ and it leads to the following feasible solution to model (6):

$\lambda_{j}^{*}, \quad j=1, \ldots, n$,

$s_{i}^{+}, \quad i=1, \ldots, m$;

$s_{r}^{-}, r=1, \ldots, s$.

(ii) Non-negativity of the optimal objective function value of model (6): 
The proof is trivial.

(iii) Boundedness of the optimal objective function value of model (6):

Let $\left(\lambda_{j}^{*}, j=1, \ldots, n ; s_{i}^{+^{*}}, i=1, \ldots, m ; s_{r}^{-*}, r=1, \ldots, s\right)$ be the optimal solution of $(6)$. The proof is by contradiction.

Assume that the optimal objective function value of model (6) is unbounded. This implies that there exists at least one unbounded value in $\left(s_{i}^{+^{*}}, i=1, \ldots, m, s_{r}^{-*}, r=1, \ldots, s\right)$. Without loss of generality, assume that $s_{t}^{-*}=\infty$. Thus, the following relation follows from the second set of constraints of model (6)

$s_{t}^{-*}=\sum_{j=1}^{n} \lambda_{j}^{*}\left(y_{t j}\right)_{\alpha}^{U}-\left(\mathrm{y}_{t o}\right)_{\alpha}^{U}=\infty$

Since $\left(y_{t j}\right)_{\alpha}^{U}, j=1, \ldots, n$, is bounded, at least one $\lambda_{j}^{*}, j=1, \ldots, n$ is unbounded. Let $\lambda_{h}^{*}=\infty$ and its substitution into the first constraint of model (6) is

$\underbrace{\underbrace{\lambda_{h}\left(x_{i h}\right)_{\alpha}^{L}}_{\infty}+\underbrace{\sum_{\substack{j=1 \\ j \neq h}}^{n} \lambda_{j}^{*}\left(x_{i j}\right)_{\alpha}^{L}+s_{i}^{+}}_{\geq 0}}_{\infty}=\left(\theta_{o}^{U}\right)_{\alpha}^{*}\left(x_{i o}\right)_{\alpha}^{L}, \quad i=1, \ldots, \mathrm{m}$,

The left hand side of the above equation is infinity (unbounded) while its right hand side is bounded which is a contradiction and completes the proof. 


\section{Appendix B}

\section{Proof of Proposition 2}

(i) Feasibility of model (8):

Model (8) is solved for those DMUs whose upper efficiency scores are unity (100\%), i.e., belonging to set $E$. Model (5-2) calculates the upper efficiency score and the solution set is nonempty as proven by the following constructive proof. Consider the following point:

$$
\begin{aligned}
& \left(x_{k o}\right)_{\alpha}^{L}=\max _{1 \leq i \leq m}\left\{\left(x_{i o}\right)_{\alpha}^{L}\right\} \\
& \left(u_{1}, \ldots, u_{s}\right)=(0, \ldots, 0),\left(v_{1}, \ldots, v_{k}, \ldots, v_{m}\right)=\left(0, \ldots, \frac{1}{\left(x_{k o}\right)_{\alpha}^{L}}, \ldots, 0\right)
\end{aligned}
$$

Let $\left(\left(\theta_{o}^{U}\right)_{\alpha}^{*} ; u_{r}^{*}, r=1, \ldots, s ; v_{i}^{*}, i=1, \ldots, m\right)$ be the optimal solution of (5-2) for $\mathrm{DMU}_{\mathrm{o}}$, thus, we have:

$\sum_{i=1}^{m} v_{i}^{*}\left(x_{i o}\right)_{\alpha}^{L}=1$

$\sum_{r=1}^{s} u_{r}^{*}\left(y_{r j}\right)_{\alpha}^{U}-\sum_{i=1}^{m} v_{i}^{*}\left(x_{i j}\right)_{\alpha}^{L} \leq 0, \quad j=1, \ldots, n$.

Since $\mathrm{DMU}_{\mathrm{o}}$ belongs to set $E,\left(\theta_{o}^{U}\right)_{\alpha}^{*}=\sum_{r=1}^{s} u_{r}^{*}\left(y_{r o}\right)_{\alpha}^{U}=1$. It implies that the optimal solution of (5-2) is a feasible solution for (8).

(ii) Non-negativity of the optimal objective function value of model (8):

The proof is trivial.

(iii) Boundedness of the optimal objective function value of model (8):

Let $\left(v_{i}^{*}, i=1, \ldots, m ; u_{r}^{*}, r=1, \ldots, s\right)$ be the optimal solution of (8). The proof is by contradiction.

Let the optimal objective function value of model (8) is unbounded. This implies that at least one optimal variable is infinity. Without loss of generality, assume that $u_{t}^{*}=\infty$. Thus, we have

$$
\sum_{r=1}^{s} u_{r}^{*}\left(y_{r o}\right)_{\alpha}^{U}=\underbrace{u_{\infty}^{*}\left(y_{t o}\right)_{\alpha}^{U}}_{\infty}+\underbrace{\sum_{\substack{r=1 \\ r \neq t}}^{s} u_{r}^{*}\left(y_{r o}\right)_{\alpha}^{U}}_{\geq 0}
$$


The above constraint is contradicted with the first constraint, $\sum_{r=1}^{s} u_{r}\left(y_{r o}\right)_{\alpha}^{U}=1$, and it completes the proof. 


\section{Appendix C}

Proof. A DMU in class $E^{+}$is such that $\left(x_{i o}\right)_{\alpha}^{L}<\sum_{j=1}^{n} \lambda_{j}\left(x_{i j}\right)_{\alpha}^{U}$ for at least one $i$, or $\left(y_{r o}\right)_{\alpha}^{U}>\sum_{j=1}^{n} \lambda_{j}\left(y_{r j}\right)_{\alpha}^{L}$ for at least one $r$. Thus, constraint 1 and/or constraint 2 of (9) are violated and the problem has no feasible solution. 


\section{Appendix D}

Proof. Let us first introduce the dual of model (4-2) to prove this proposition as:

$\min \theta_{o}^{U}$

$$
\begin{array}{ll}
\text { s.t. } & \sum_{\substack{j=1 \\
j \neq o}}^{n} \lambda_{j}\left(x_{i j}\right)_{\alpha}^{U}+\lambda_{o}\left(x_{i o}\right)_{\alpha}^{L} \leq \theta_{o}^{U}\left(x_{i o}\right)_{\alpha}^{L}, i=1, \ldots, m, \\
& \sum_{\substack{j=1 \\
j \neq o}}^{n} \lambda_{j}\left(y_{r j}\right)_{\alpha}^{L}+\lambda_{o}\left(y_{r o}\right)_{\alpha}^{U} \geq\left(y_{r o}\right)_{\alpha}^{U}, \quad r=1, \ldots, s, \\
& \lambda_{j} \geq 0, \quad j=1, \ldots, n .
\end{array}
$$

Suppose that a $\mathrm{DMU}_{\mathrm{o}}$ is in class $E^{-}$. Due to the inefficiency of $\mathrm{DMU}_{\mathrm{o}}, \lambda_{o}^{*}=0$ and $0<\theta_{o}^{U^{*}}<1$ in the optimal solution of model (11). Therefore, the constraints of (11) can be converted to

$$
\left\{\begin{array}{l}
\sum_{\substack{j=1 \\
j \neq o}}^{n} \lambda_{j}^{*}\left(x_{i j}\right)_{\alpha}^{U}<\left(x_{i o}\right)_{\alpha}^{L}, i=1, \ldots, m, \\
\sum_{\substack{j=1 \\
j \neq o}}^{n} \lambda_{j}^{*}\left(y_{r j}\right)_{\alpha}^{L} \geq\left(y_{r o}\right)_{\alpha}^{U}, r=1, \ldots, s,
\end{array}\right.
$$

which is equivalent to the following slack-variable formulation:

$$
\left\{\begin{array}{l}
\sum_{j=1}^{n} \lambda_{j}^{*}\left(x_{i j}\right)_{\alpha}^{U}+s_{i}^{+}=\left(x_{i o}\right)_{\alpha}^{L}, i=1, \ldots, m, \\
\sum_{j=1}^{n} \lambda_{j}^{*}\left(y_{r j}\right)_{\alpha}^{L}-s_{r}^{-}=\left(y_{r o}\right)_{\alpha}^{U}, r=1, \ldots, s,
\end{array}\right.
$$

Consequently, $\left(\lambda_{j}^{*}, s_{i}^{+}, s_{r}^{-}\right)$is a feasible solution for model (9). 


\section{Appendix E}

Proof. The use of $\varepsilon_{i}^{v}$ and $\varepsilon_{r}^{u}$ as the lower bounds for the weights in model (4-2) cannot guarantee feasibility. According to Step 3 of the Khoshfetrat and Daneshvar (2011) method, we need to individually solve $|S| \times(m+s)^{12}$ models (10) for calculating the lower bounds of the input and output weights, $\varepsilon_{i}^{v}$ and $\varepsilon_{r}^{u}$ that are incorporated into model (4-2). Due to solving $|S| \times(m+s)$ models without interacting with each other, it is possible that dual weights $v_{i} \geq \varepsilon_{i}^{v}$ $\left(u_{r} \geq \varepsilon_{r}^{u}\right)$ jeopardize the feasibility. We prove this infeasibility problem simply by existence, using the numerical example in Khoshfetrat and Daneshvar (2011, p.343). C, F and H are the weakly efficient units and that $\varepsilon$ for $v_{1}, u_{1}$ and $u_{2}$ are set as $0.1,0.2$ and 0.1 , respectively ${ }^{13}$. The corresponding upper efficiency bound of model (4-2) is infeasible for all DMUs with the given $\varepsilon$ for the weights.

\footnotetext{
${ }^{12}|S|$ is the number of members in set $S$.

${ }^{13}$ This result is reported in Khoshfetrat and Daneshvar (2011) although the method is not able to reveal weakly efficient DMUs.
} 


\section{Appendix F}

\$ONTEXT

This program is written by Hatami-Marbini et al. as a part of the paper The Role of Multiplier Bounds in Fuzzy Data Envelopment Analysis \$OFFTEXT

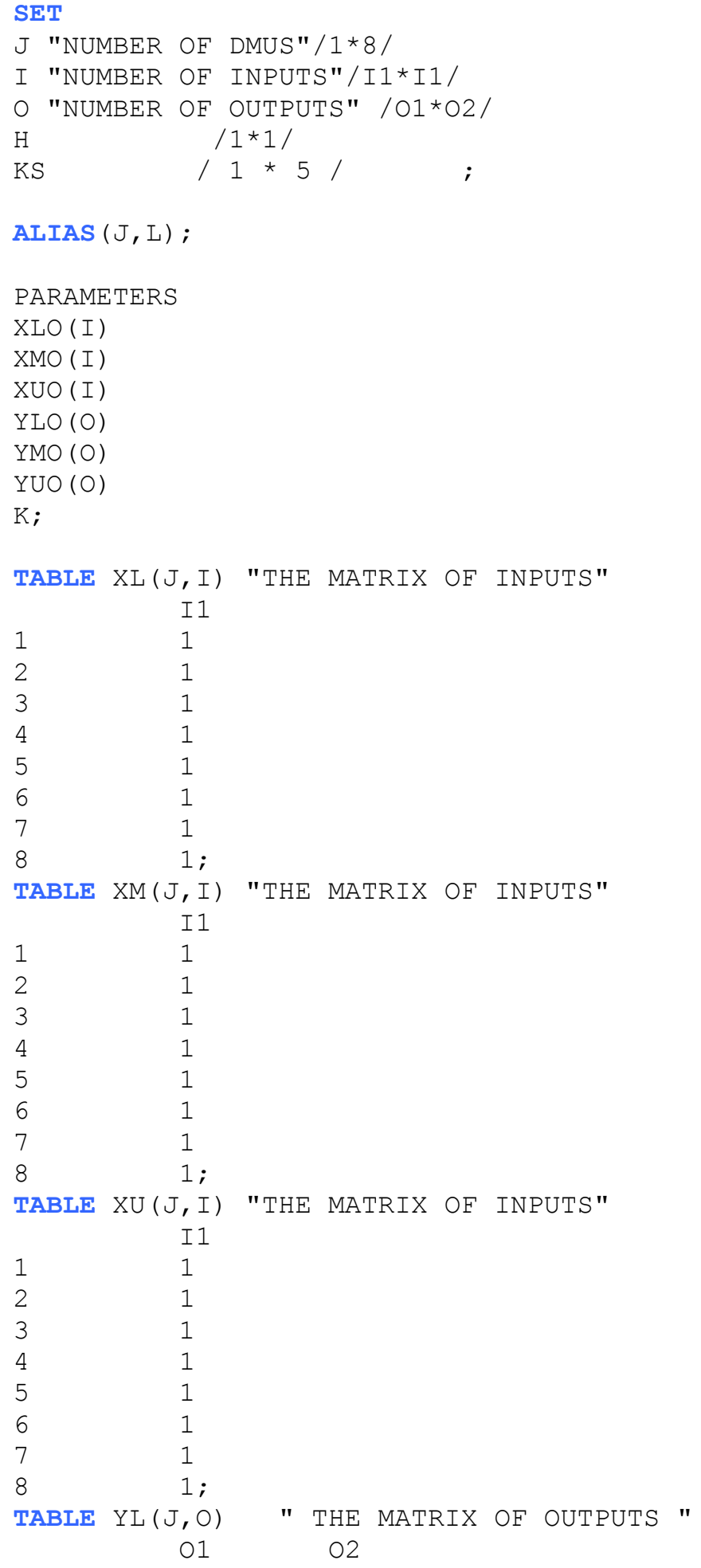




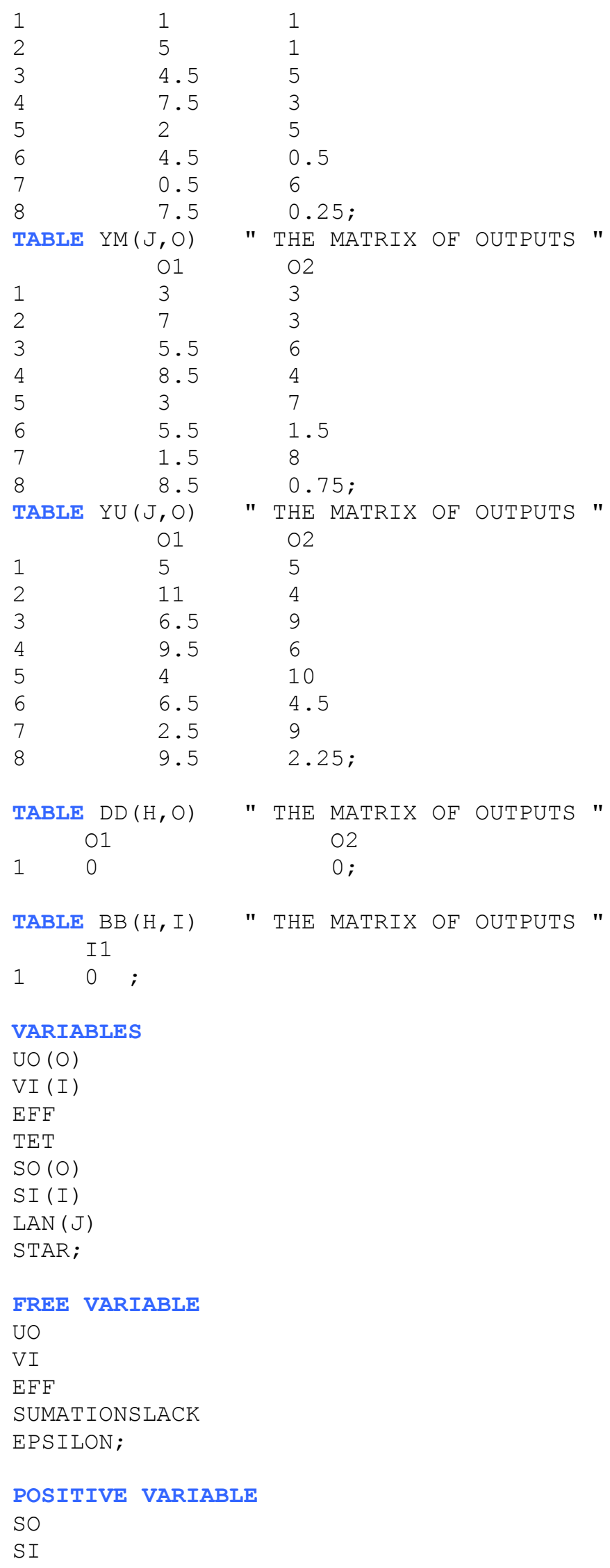


LAN;

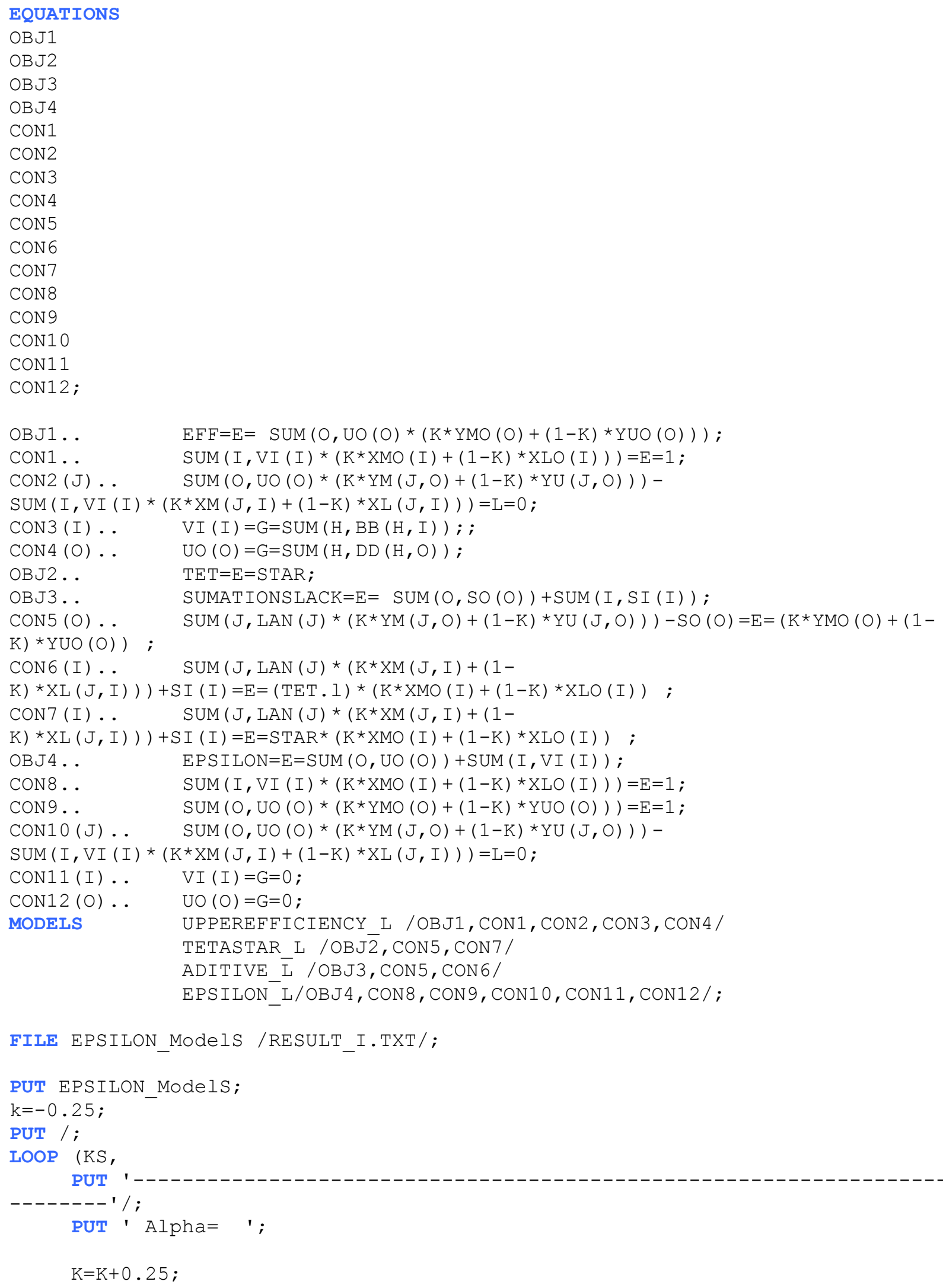




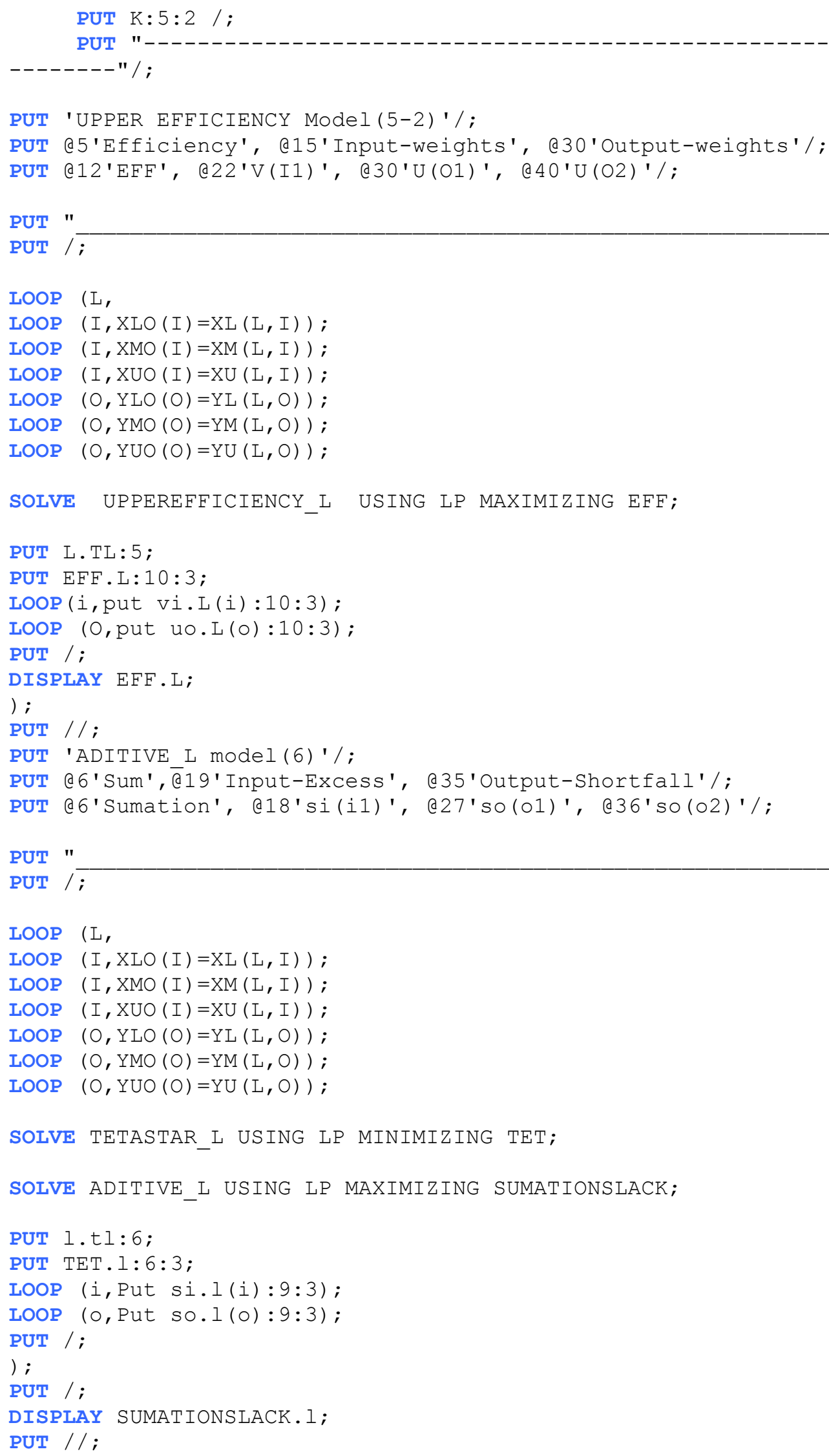




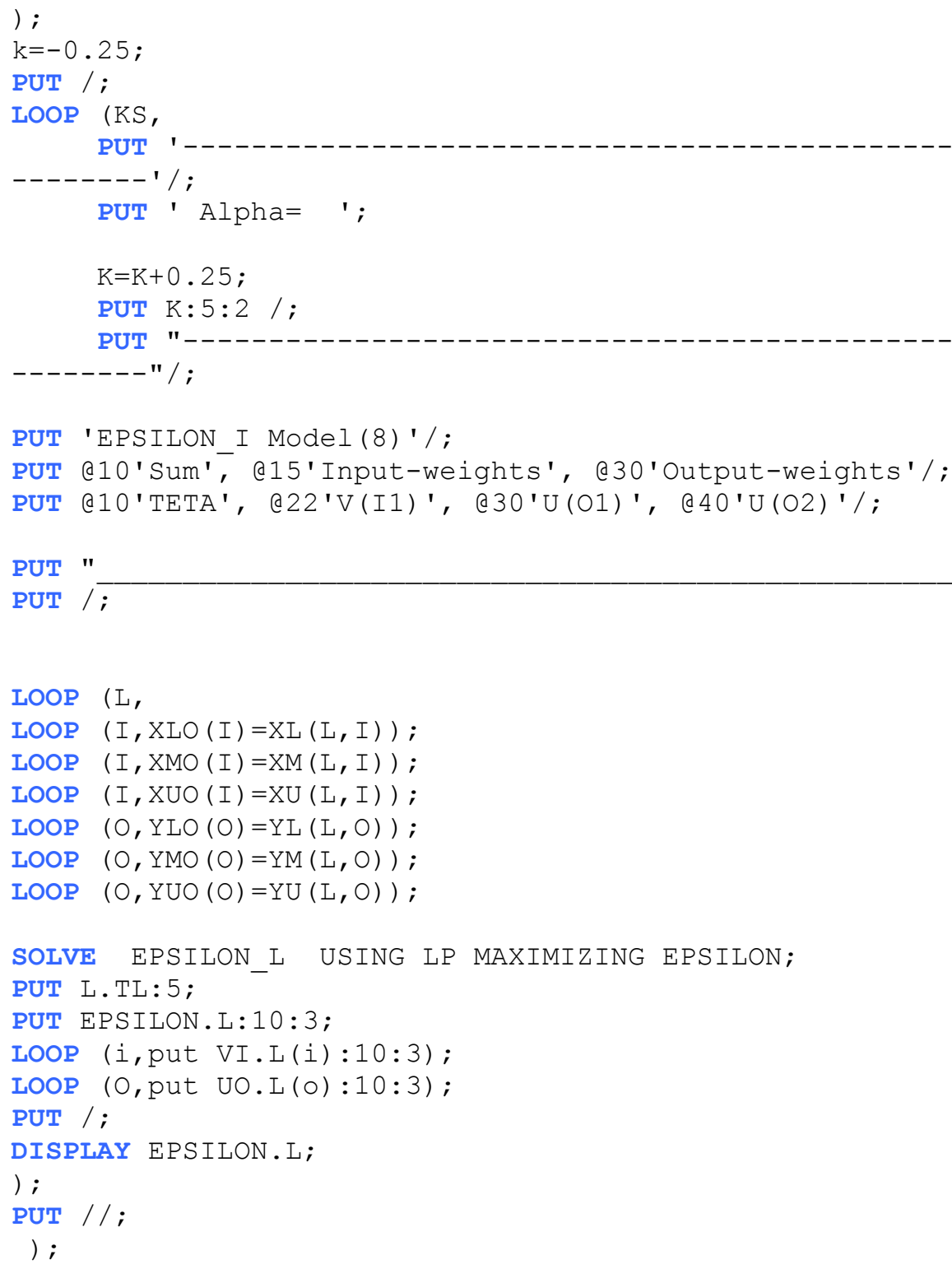




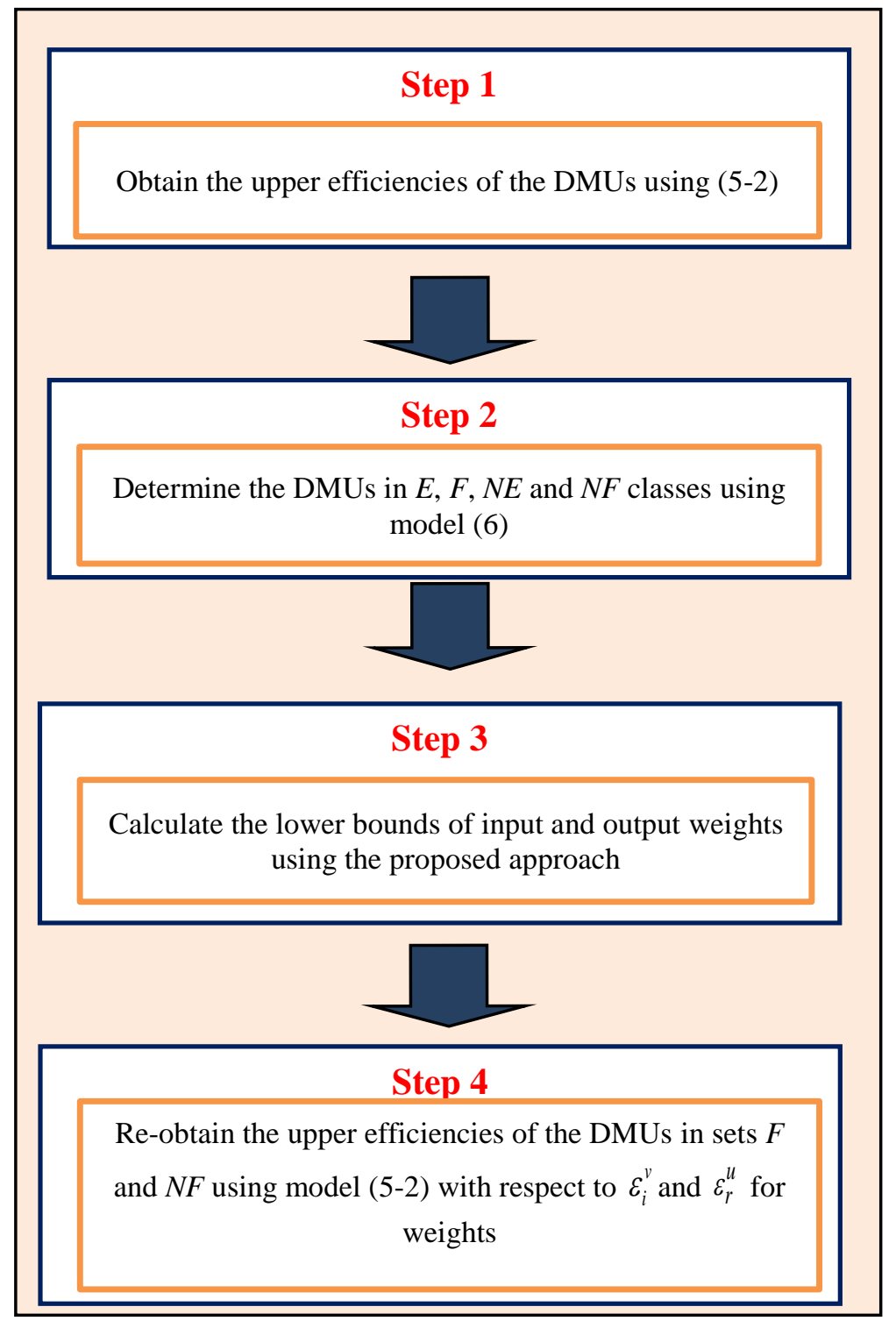

Figure 1. The proposed framework. 


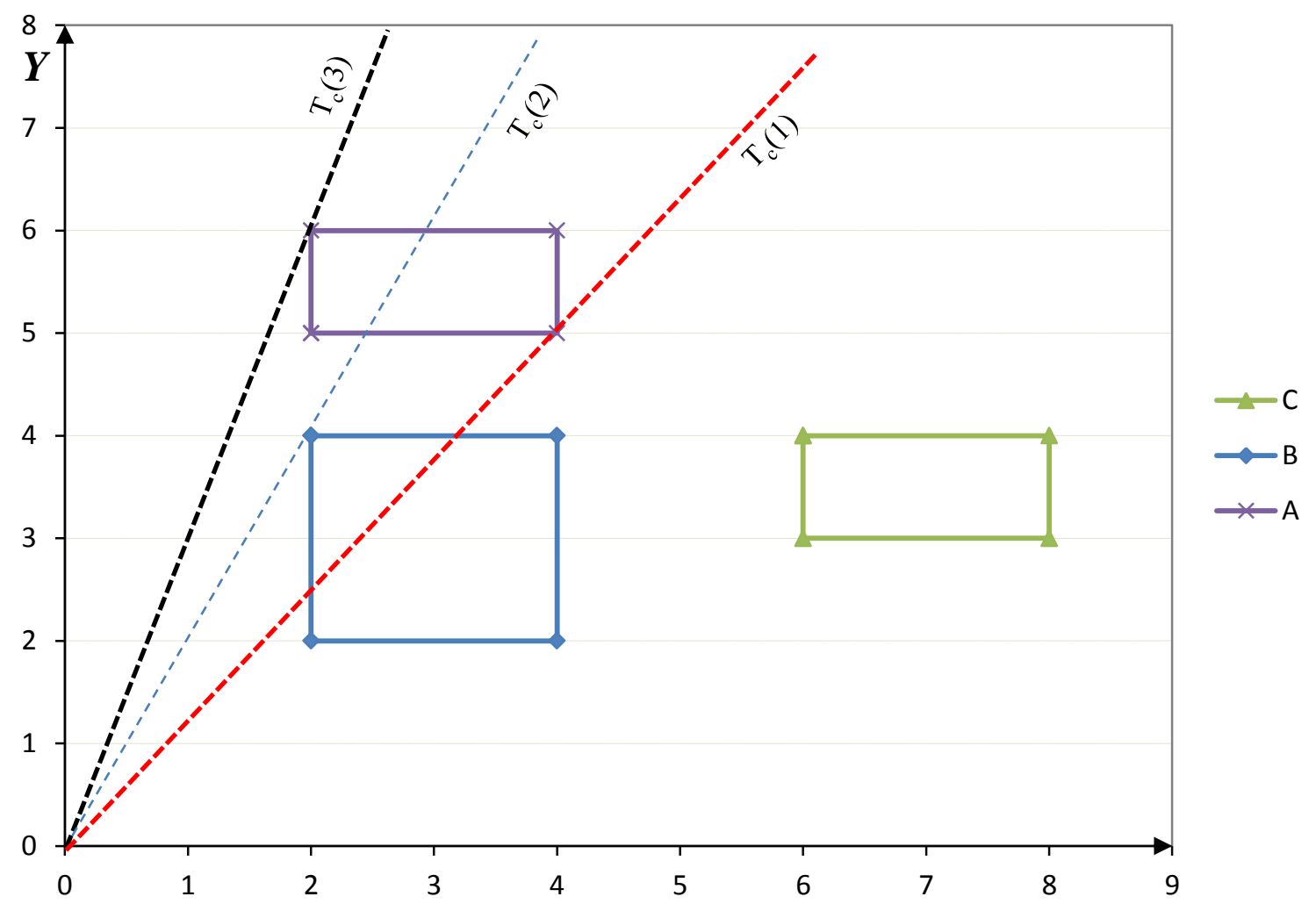

Figure 2. Frontiers by Khoshfetrat and Daneshvar (2011), Despotis and Smirlis (2002) and Wang et al. (2005). 


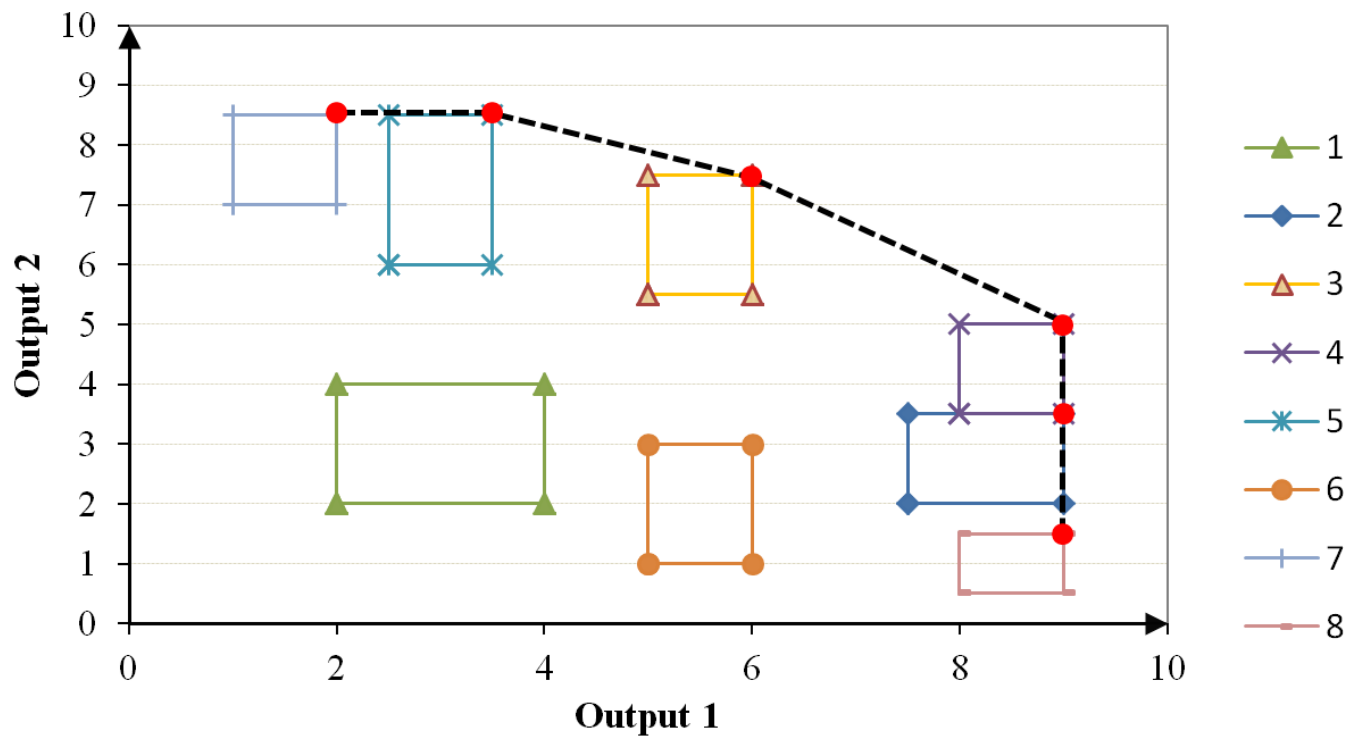

Figure 3. The proposed output set of the numerical example for $\alpha=0.5$. 
Table 1. Input and output data for eight DMUs

\begin{tabular}{llll}
\hline DMU & Input & Output 1 & Output 2 \\
\hline $\mathbf{1}$ & $(1,1,1)$ & $(1,3,5)$ & $(1,3,5)$ \\
$\mathbf{2}$ & $(1,1,1)$ & $(5,7,11)$ & $(1,3,4)$ \\
$\mathbf{3}$ & $(1,1,1)$ & $(4.5,5.5,6.5)$ & $(5,6,9)$ \\
$\mathbf{4}$ & $(1,1,1)$ & $(7.5,8.5,9.5)$ & $(3,4,6)$ \\
$\mathbf{5}$ & $(1,1,1)$ & $(2,3,4)$ & $(5,7,10)$ \\
$\mathbf{6}$ & $(1,1,1)$ & $(4.5,5.5,6.5)$ & $(0.5,1.5,4.5)$ \\
$\mathbf{7}$ & $(1,1,1)$ & $(0.5,1.5,2.5)$ & $(6,8,9)$ \\
$\mathbf{8}$ & $(1,1,1)$ & $(7.5,8.5,9.5)$ & $(0.25,0.75,2.25)$ \\
\hline
\end{tabular}


Table 2. Interval data of the DMUs with regards to different $\alpha$-level

\begin{tabular}{|c|c|c|c|c|}
\hline$\overline{\text { DMU }}$ & $\alpha$ & Input & Output 1 & Output 2 \\
\hline \multirow[t]{5}{*}{1} & 0 & 1 & {$[1,5]$} & {$[1,5]$} \\
\hline & 0.25 & 1 & {$[1.5,4.5]$} & {$[1.5,4.5]$} \\
\hline & 0.5 & 1 & {$[2,4]$} & {$[2,4]$} \\
\hline & 0.75 & 1 & {$[2.5,3.5]$} & {$[2.5,3.5]$} \\
\hline & 1 & 1 & {$[3,3]$} & {$[3,3]$} \\
\hline \multirow[t]{5}{*}{2} & 0 & 1 & {$[5,11]$} & {$[1,4]$} \\
\hline & 0.25 & 1 & {$[5.5,10]$} & {$[1.5,3.75]$} \\
\hline & 0.5 & 1 & {$[7.5,9]$} & {$[2,3.5]$} \\
\hline & 0.75 & 1 & {$[6.5,8]$} & {$[2.5,3.25]$} \\
\hline & 1 & 1 & {$[7,7]$} & {$[3,3]$} \\
\hline \multirow[t]{5}{*}{3} & 0 & 1 & {$[4.5,6.5]$} & {$[5,9]$} \\
\hline & 0.25 & 1 & {$[4.75,5.75]$} & {$[5.25,8.5]$} \\
\hline & 0.5 & 1 & {$[5,6]$} & {$[5.5,7.5]$} \\
\hline & 0.75 & 1 & {$[5.25,5.75]$} & {$[5.75,6.75]$} \\
\hline & 1 & 1 & {$[5.5,5.5]$} & {$[6,6]$} \\
\hline \multirow[t]{5}{*}{4} & 0 & 1 & {$[7.5,9.5]$} & {$[3,6]$} \\
\hline & 0.25 & 1 & {$[7.75,9.25]$} & {$[3.25,5.5]$} \\
\hline & 0.5 & 1 & {$[8,9]$} & {$[3.5,5]$} \\
\hline & 0.75 & 1 & {$[8.25,8.75]$} & {$[3.75,4.5]$} \\
\hline & 1 & 1 & {$[8.5,8.5]$} & {$[4,4]$} \\
\hline \multirow[t]{5}{*}{5} & 0 & 1 & {$[2,4]$} & {$[5,10]$} \\
\hline & 0.25 & 1 & {$[2.25,3.75]$} & {$[5.5,9.25]$} \\
\hline & 0.5 & 1 & {$[2.5,3.5]$} & {$[6,8.5]$} \\
\hline & 0.75 & 1 & {$[2.75,3.25]$} & {$[6.5,7.75]$} \\
\hline & 1 & 1 & {$[3,3]$} & {$[7,7]$} \\
\hline \multirow[t]{5}{*}{6} & 0 & 1 & {$[4.5,6.5]$} & {$[0.5,4.5]$} \\
\hline & 0.25 & 1 & {$[4.75,6.25]$} & {$[0.75,3.75]$} \\
\hline & 0.5 & 1 & {$[5,6]$} & {$[1,3]$} \\
\hline & 0.75 & 1 & {$[5.25,5.75]$} & {$[1.25,2.25]$} \\
\hline & 1 & 1 & {$[5.5,5.5]$} & {$[1.5,1.5]$} \\
\hline \multirow[t]{5}{*}{7} & 0 & 1 & {$[0.5,2.5]$} & {$[6,9]$} \\
\hline & 0.25 & 1 & {$[0.75,2.25]$} & {$[6.5,8.75]$} \\
\hline & 0.5 & 1 & {$[1,2]$} & {$[7,8.5]$} \\
\hline & 0.75 & 1 & {$[1.25,1.75]$} & {$[7.5,8.25]$} \\
\hline & 1 & 1 & {$[1.5,1.5]$} & {$[8,8]$} \\
\hline \multirow[t]{5}{*}{8} & 0 & 1 & {$[7.5,9.5]$} & {$[0.25,2.25]$} \\
\hline & 0.25 & 1 & {$[7.75,9.25]$} & {$[0.375,1.875]$} \\
\hline & 0.5 & 1 & {$[8,9]$} & {$[0.5,1.5]$} \\
\hline & 0.75 & 1 & {$[8.25,8.75]$} & {$[0.625,1.125]$} \\
\hline & 1 & 1 & {$[8.5,8.5]$} & {$[0.75,0.75]$} \\
\hline
\end{tabular}


Table 3. The upper bound of the efficiencies for eight DMUs

\begin{tabular}{llllll}
\hline DMU & $\alpha=0$ & $\alpha=0.25$ & $\alpha=0.5$ & $\alpha=0.75$ & $\alpha=1$ \\
\hline $\mathbf{1}$ & 0.645 & 0.617 & 0.587 & 0.554 & 0.517 \\
$\mathbf{2}$ & 1.000 & 1.000 & 1.000 & 0.914 & 0.824 \\
$\mathbf{3}$ & 1.000 & 1.000 & 1.000 & 1.000 & 1.000 \\
$\mathbf{4}$ & 1.000 & 1.000 & 1.000 & 1.000 & 1.000 \\
$\mathbf{5}$ & 1.000 & 1.000 & 1.000 & 1.000 & 0.971 \\
$\mathbf{6}$ & 0.710 & 0.678 & 0.667 & 0.657 & 0.647 \\
$\mathbf{7}$ & 0.900 & 0.946 & 1.000 & 1.000 & 1.000 \\
$\mathbf{8}$ & 0.864 & 0.925 & 1.000 & 1.000 & 1.000 \\
\hline
\end{tabular}


Table 4. The non-zero results of model (6) for DMUs in set F at different $\alpha$-level

\begin{tabular}{lllll}
\hline$\alpha$-level & DMU & $s_{1}^{+}$ & $s_{1}^{-}$ & $s_{2}^{-}$ \\
\hline$\alpha=0.5$ & 2 & 0 & 0 & 1.5 \\
$\alpha=0.5$ & 7 & 0 & 1.5 & 0 \\
$\alpha=0.5$ & 8 & 0 & 0 & 3.5 \\
$\alpha=0.75$ & 8 & 0 & 0 & 3.375 \\
$\alpha=1$ & 8 & 0 & 0 & 3.25 \\
\hline
\end{tabular}


Table 5. The non-zero results of model (6) for DMUs in set NF at different $\alpha$-level

\begin{tabular}{lllll}
\hline$\alpha$-level & DMU & $s_{1}^{+}$ & $s_{1}^{-}$ & $s_{2}^{-}$ \\
\hline$\alpha=0$ & 7 & 0 & 1.1 & 0 \\
$\alpha=0$ & 8 & 0 & 0 & 1.205 \\
$\alpha=0.25$ & 7 & 0 & 1.297 & 0 \\
$\alpha=0.25$ & 8 & 0 & 0 & 1.594 \\
$\alpha=0.5$ & 6 & 0 & 0 & 0.333 \\
$\alpha=0.75$ & 2 & 0 & 0 & 0.864 \\
$\alpha=0.75$ & 6 & 0 & 0 & 0.707 \\
$\alpha=1$ & 2 & 0 & 0 & 0.294 \\
$\alpha=1$ & 6 & 0 & 0 & 1.088 \\
\hline
\end{tabular}


Table 6 . The lower bounds of weights

\begin{tabular}{lccc}
\hline DMU & $\varepsilon_{1}^{v}$ & $\varepsilon_{1}^{u}$ & $\varepsilon_{2}^{u}$ \\
\hline$\alpha=0$ & 1.000 & 0.034 & 0.054 \\
$\alpha=0.25$ & 1.000 & 0.037 & 0.037 \\
$\alpha=0.5$ & 1.000 & 0.040 & 0.080 \\
$\alpha=0.75$ & 1.000 & 0.038 & 0.090 \\
$\alpha=1$ & 1.000 & 0.057 & 0.103 \\
\hline
\end{tabular}


Table 7. The upper bound of the efficiencies for eight DMUs

\begin{tabular}{llllll}
\hline DMU & $\alpha=0$ & $\alpha=0.25$ & $\alpha=0.5$ & $\alpha=0.75$ & $\alpha=1$ \\
\hline $\mathbf{1}$ & 0.645 & 0.617 & 0.587 & 0.554 & 0.517 \\
$\mathbf{2}$ & 1.000 & 1.000 & 0.880 & 0.837 & 0.793 \\
$\mathbf{3}$ & 1.000 & 1.000 & 1.000 & 1.000 & 1.000 \\
$\mathbf{4}$ & 1.000 & 1.000 & 1.000 & 1.000 & 1.000 \\
$\mathbf{5}$ & 1.000 & 1.000 & 1.000 & 1.000 & 0.971 \\
$\mathbf{6}$ & 0.710 & 0.678 & 0.640 & 0.594 & 0.535 \\
$\mathbf{7}$ & 0.863 & 0.898 & 0.940 & 1.000 & 1.000 \\
$\mathbf{8}$ & 0.797 & 0.866 & 0.720 & 0.696 & 0.665 \\
\hline
\end{tabular}

